$\mathrm{F}$

Flammable Gas Safety Program

\title{
Organic Analysis and Analytical Methods Development: FY 1995 Progress Report
}

Technical Task Leader: J. A. Campbell
S, A. Clauss
K. E. Grant
V. Hoopes
G. M. Mong
J. Rau
R. Scheele
K. L. Wahl

September 1995

Prepared for Westinghouse Hanford Company with the U.S. Department of Energy

Contract DE-AC06-76RLO 1830

Pacific Northwest Laboratory

Operated for the U.S. Department of Energy

by Battelle Memorial Institute 


\section{DISCLA'IMER}

This report was prepared as an account of work sponsored by an agency of the United States Government. Neither the United States Government nor any agency thereof, nor Battelle Memorial Institute, nor any of their employees, makes any warranty, expressed or implied, or assumes any legal liability or responsibility for the accuracy, completeness, or usefulness of any information; apparatus, product, or process disclosed, or represents that its use would not infringe privately owned rights. Reference herein to any specific commercial product, process, or service by trade name; trademark, manufacturer, or otherwise does, not necessarily constitute or imply its endorsement, recommendation, or favoring by the United States Government or any àgency thereof, or Battelle Memorial Institute. The views and opinion's of authors.expressed herein do not necessarily state or reflect those of the United States Government or any agency thereof.

\section{PACIFIC NORTHWEST LABORATORY operated by}

BATTELLE MEMÓRIAL INSTITUT́TE is for the

UNITED STATES DEPARTMENTT OF ENERGY . under Contract DE-ACO6-76RLO'1830 3

Printed in the United States of America

Available to DOE and DOE contractors from the

Office of Scientific and Technical-Information, P.O. Box 62, Oak Ridge, iN 37831; prices available from (615) 576-8401. FTS 626-8401.

Available to the public from the National Technical Information Service, U.S. Department of Commerce, 5285 Port Royal Rd., Springfield, VA 22161.

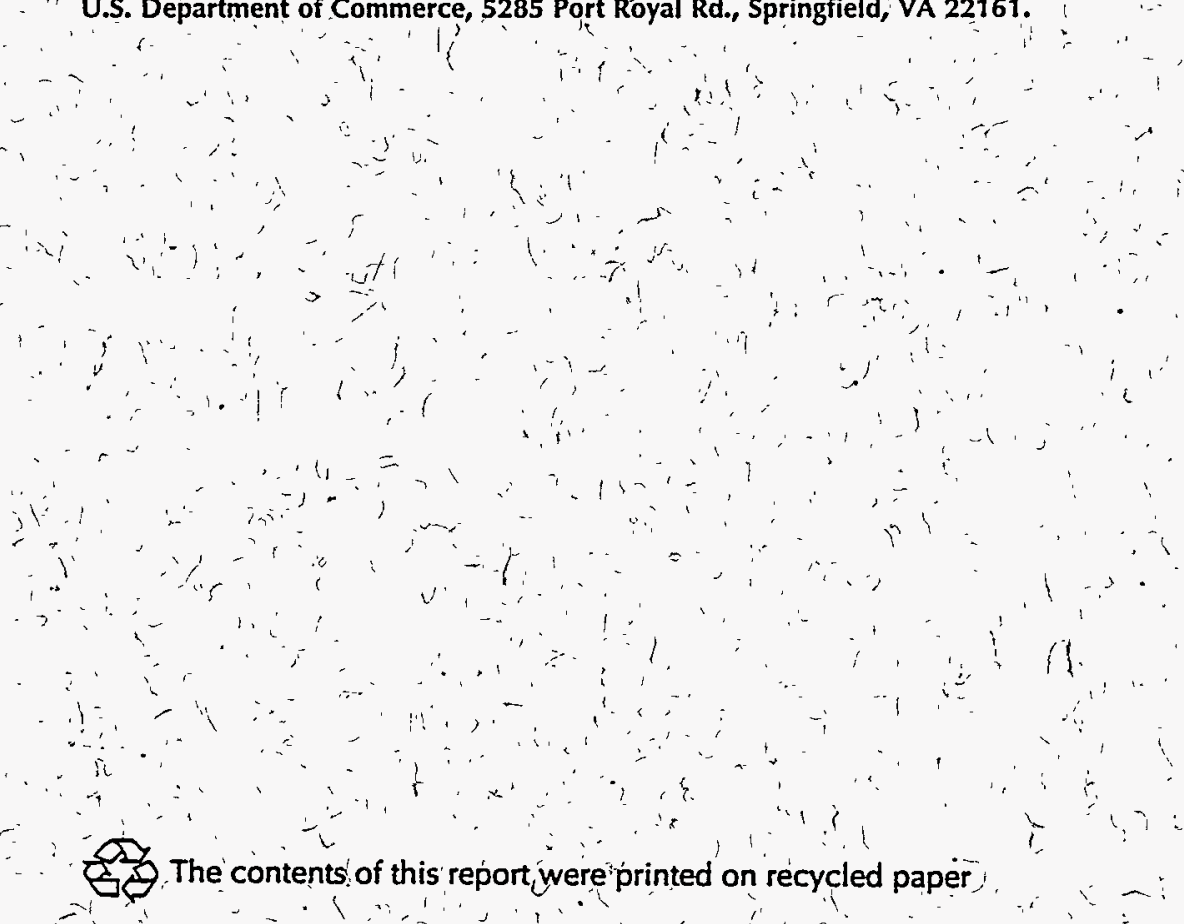




\section{Flammable Gas Safety Program}

\section{Organic Analysis and Analytical Methods Development: FY 1995 Progress Report}

Technical Task Leader: J. A. Campbell

Report contributors:

S. A. Clauss

K. E. Grant

V. Hoopes

G. M. Mong

J. Rau

R. Steele

K. L. Wahl

September 1, 1995

\footnotetext{
Prepared for

Westinghouse Hanford Company

Richland, Washington 99352

Pacific Northwest Laboratory

Richland, Washington 99352
} 



\begin{abstract}
This report describes the status of organic analyses and developing analytical methods to account for the organic components in Hanford waste tanks, with particular emphasis on tanks assigned to the Flammable Gas Watch List. The methods that have been developed are illustrated by their application to samples obtained from Tank 241-SY-103 (Tank 103-SY). The analytical data are to serve as an example of the status of methods development and application.

Samples of the convective and nonconvective layers from Tank 103-SY were analyzed for total organic carbon (TOC). The TOC value obtained for the nonconvective layer using the hot persulfate method was $10,500 \mu \mathrm{g} \mathrm{C} / \mathrm{g}$. The TOC value obtained from samples of Tank $101-\mathrm{SY}$ was $11,000 \mu \mathrm{g} \mathrm{C} / \mathrm{g}$. The average value for the TOC of the convective layer was $6400 \mu \mathrm{g} \mathrm{C} / \mathrm{g}$. Chelator and chelator fragments in Tank 103-SY samples were identified using derivatization gas chromatography/mass spectrometry (GC/MS). Organic components were quantified using GC/flame ionization detection. Major components in both the convective and nonconvective-layer samples include ethylenediaminetetraacetic acid (EDTA), nitrilotriacetic acid (NTA), succinic acid, nitrosoiminodiacetic acid (NIDA), citric acid, and ethylenediaminetriacetic acid (ED3A). Preliminary results also indicate the presence of C16 and C18 carboxylic acids in the nonconvective-layer sample. Oxalic acid was one of the major components in the nonconvective layer as determined by derivatization $\mathrm{GC} /$ flame ionization detection.
\end{abstract}

Recovery studies on samples from Tank 101-SY in the derivatization gas chromatography/mass spectrometry (GC/MS) procedure for the analysis of chelators, chelator fragments, and carboxylic acids using standard addition and deuterated internal standards were completed. The recovery yields vary from $101 \%$ for succinic acid to $27 \%$ for $\mathrm{N}$-(2-hydroxyethyl)ethylenediaminetriacetic acid (HEDTA). The low recovery for HEDTA is due to the formation of components during the derivatization procedure that are not amenable to GC analysis. This was substantiated by using alternate derivatization and analysis techniques.

The use of a cation exchange material was assimilated into the sample preparation procedure for the analysis of tank waste. Results showed that the use of cation exchange to reduce the radioactivity levels did not introduce or reduce any organic carbon. In addition, the radioactivity level of ${ }^{137} \mathrm{Cs}$ was reduced by a factor of approximately 300 , and the level of ${ }^{90} \mathrm{Sr}$ was reduced by a factor of 10 to 15 in convective-layer samples from Tank 103-SY.

Low-molecular weight acids were previously analyzed using liquid chromatography (LC) with ultraviolet (UV) detection. The high concentration of nitrate and nitrite interfered with quantitating several of the acids, particularly citric acid. However, ion chromatography has been demonstrated to be an effective method for the assay of both succinate and citrate ions.

Due to interference from nitrate and nitrite in the analysis of low-molecular weight acids, two tactics were explored for removing inorganic anions from a simulant matrix. This requires that the samples be acidified and introduced through the support media, with the neutral organics remaining on the column. This was felt to be a promising method that would allow the nitrate/nitrite components to be rinsed from the desired components. Another method using sulfamic acid to convert nitrite to nitrogen gas was evaluated. The unfortunate aspect of such treatments is the necessity of acidifying the sample; this leads to concurrent $\mathrm{NO}_{x}$ gas generation and probable alteration of certain target organics with active amines $\{$ e.g, iminodiacetic acid (IDA) $\}$ to nitroso compounds. Such techniques for nitrate/nitrite removal were not found to be necessary with the use of ion chromatography.

The derivatization.GC/MS method currently used for analyzing chelators and chelator fragments has been extended for the analysis of surfactants, long-chain carboxylic acids. Other surfactants, including long-chain sulphonates, may be analyzed using thermospray liquid chromatography (LC)/MS.

Analytical support was also provided for the simulated waste studies under the Gas Generation Task (Sam Bryan-Task Leader) to determine the extent of degradation and to identify degradation products. Degradation products from the heating and irradiation of HEDTA were identified using ion chromatography. 



\section{Executive Summary}

This report describes the status of analyses and developing analytical methods to account for the organic constituents in Hanford waste tanks. Particular emphasis was placed on those tanks that have been assigned to the Flammable Gas Watch List. The methods that have been developed are illustrated by their application to samples obtained from Tank 241-SY-103 (103-SY). The marked improvement in ability to account for organic carbon in 101-SY samples was a result of significant improvement in techniques for isolating organic constituents relatively free from radioactive contamination and for improvements in derivatization methodology. The methodology has been extended to the analysis of samples from Tank 103-SY, and the results are documented in this report. In addition, recovery studies using samples from Tank 101-SY and studies of simulated wastes are also included in this report.

The drainable liquids from segments 2-7 were composited to comprise the convective-layer sample from Tank 103-SY. The nonconvective-layer sample was composed of solids from segments 1014. Total organic carbon (TOC) values were determined by the hot persulfate method for the convective and nonconvective layer samples from Tank 103-SY. The TOC value for the nonconvective layer was $10,500 \mu \mathrm{g} \mathrm{C} / \mathrm{g}$, which was very similar to TOC results from Tank 101-SY. The average value for TOC for the convective layer sample was $6,400 \mu \mathrm{g} \mathrm{C} / \mathrm{g}$. It should be noted that the hot persulfate method is not a good technique for acetone, butanol, NPH, benzene, and solid hydrocarbons. Samples from Tank 103-SY have been analyzed for organic constituents.

The convective layer and nonconvective layer-samples were analyzed using derivatization gas chromatography/mass spectrometry (GC/MS) for chelator and chelator fragments. The major components in the convective layer include ethylenediaminetetraacetic acid (EDTA), ethylenediaminetriacetic acid (ED3A), N-nitrosoiminodiacetic acid (NIDA), nitrilotriacetic acid (NTA), citric acid (CA), and succinic acid (SA). Chelator and chelator fragments were quantified using gas chromatography/flame ionization detection. In addition, low-molecular weight acids were quantified using liquid chromatography with ultraviolet detection. The results were similar to those obtained by the 222-S laboratory (Rice 1995). Table S.1 summarizes the data for low-molecular weight acids, chelators, and chelator fragments of samples from Tank 103-SY. Table S.2 summarizes the preliminary data from samples of the convective and nonconvective layer from Tank 101-SY (Campbell et al. 1994). The data represented in Table S.2 are average values obtained for the convective and nonconvective layer samples. These component types constitute the majority of the carbon accounted for.

The chelators and chelator fragments comprise $23.4 \%$ and $18.3 \%$ of the TOC in the convective and nonconvective-layer samples from Tank 103-SY, respectively. In contrast, the chelators and chelator fragments constitute $44 \%$ and $26 \%$ of the TOC in the convective and nonconvective-layer samples from Tank 101-SY, respectively. Low-molecular weight acids comprise $28.1 \%$ and $80.9 \%$ of the TOC in the convective and nonconvective-layers samples from Tank 103-SY, respectively. For samples from Tank 101-SY, low-molecular weight acids make up 35\% and 57\% of the convective and nonconvective-layer samples, respectively. The TOC accountability is $78-99 \%$ for the convective and nonconvective-layer samples from Tank 101-SY and the nonconvective-layer sample from Tank 103-SY. At present with limited sample analyses, the TOC accountability for the convective-layer sample from Tank 103-SY is $52 \%$. Additional samples will be analyzed.

Recovery studies in the derivatization GC/mass spectrometry (MS) procedure for the analysis of chelators and chelator fragments using standard addition techniques and deuterated internal standards were completed with samples from Tank 101-SY. Results from the introduction of deuterated internal standards in the tank-waste matrix showed no scrambling or exchange of deuterium. Recoveries of the major components range from $101 \%$ for succinic acid to $27 \%$ for $\mathrm{N}$-(2-hydroxyethyl)ethylenediaminetriacetic acid (HEDTA). Results have shown that when derivatized with boron trifluoride $\left(\mathrm{BF}_{3}\right) / \mathrm{methanol}$, a portion of the available HEDTA reacts to form a compound that is thought to be too polar to migrate through a GC column. This was confirmed by using other derivatization techniques such as silylation. 
Radioactivity levels in tank-waste samples were reduced with the use of cation exchange before removal from the hot cell facilities. This additional step to the sample-preparation procedure was probably the single most important fact in increasing the \%TOC accounted for. This step allowed the drying and derivatization to be performed in a fume hood; parameters important for increased derivatization yields could be better controlled and monitored. This technique was applied to samples from Tank 103-SY. The radioactivity level of ${ }^{137} \mathrm{Cs}$ was reduced by a factor of approximately 300 , and the level of ${ }^{90} \mathrm{Sr}$ was reduced by a factor of 10 to 15 in the convective-layer samples. For the nonconvectivelayer samples, the ${ }^{137} \mathrm{Cs}$ was reduced by approximately a factor of 900 , and the level of ${ }^{90} \mathrm{Sr}$ was reduced by a factor of 13 . In addition, apparently no organic carbon was introduced or removed from the waste samples.

Liquid chromatography (LC) with ultraviolet (UV) detection was previously used for the analysis of low-molecular weight acids. In order to quantify organic acids, two procedures were required. For oxalic acid, a basic mobile phase was used. For acetic, formic, and glycolic acids, an acidic mobile phase was utilized. Due to the presence of high concentrations of nitrite and nitrate in actual waste samples, citrate, succinate, and glycolate were difficult to quantitate. Dilution of the sample was not a viable option due to the relative insensitivity of UV detection for organic acids. An analysis technique for lowmolecular weight acids has been extended from LC and involves ion chromatography with a gradient elution and suppressed conductivity detection. This method has provided a single, faster, and cheaper method for the analysis of low-molecular weight acids.

Table S.1. Carbon Accounted for by Chelators, Chelator Fragments, and Low-Molecular-Weight Acids in Tank 103-SY Convective and Nonconvective Layer Samples

\begin{tabular}{lllc} 
Sample & Chelators & $\begin{array}{l}\text { Low-Molecular- } \\
\text { Weight Acids }\end{array}$ & \%TOC Accounted For \\
\cline { 2 - 3 } Convective & $1.5(23.4 \%)$ & $1.8(28.1 \%)$ & 51.5 \\
Nonconvective & $1.7(18.3 \%)$ & $7.6(80.9 \%)$ & 99.2
\end{tabular}

Table S.2. Carbon Accounted for by Chelators, Chelator Fragments, Low-Molecular-Weight Acids and NPH in Tank 101-SY Samples (mg C/g sample)

\begin{tabular}{|c|c|c|c|}
\hline Sample & Chelators $^{(2)}$ & $\begin{array}{l}\text { Low-Molecular- } \\
\text { Weight Acids }^{(\mathbf{b})}\end{array}$ & $\begin{array}{c}\text { \%TOC } \\
\text { Accounted For } \\
\end{array}$ \\
\hline $\begin{array}{l}\text { Convective } \\
\text { Nonconvective }\end{array}$ & $\begin{array}{l}4.8(44 \%)^{(\mathrm{c})} \\
2.9(26 \%)\end{array}$ & $\begin{array}{l}3.7(35 \%) \\
6.3(57 \%)\end{array}$ & $\begin{array}{l}78 \\
83\end{array}$ \\
\hline
\end{tabular}

(a) Includes chelators, chelator fragments, nitrosated chelator material, and several carboxylic acids.

(b) Low-molecular-weight acids include acetic, glycolic, oxalic, and formic.

(c) Parentheses give percent of TOC accounted for by analyte category. 
Derivatization GC/MS has been used successfully for analyzing chelators and chelator fragments in waste samples (Campbell et al: 1994). This method has been extended for analyzing long-chain carboxylic acids, or surfactants. Carboxylic acids of C16 and C18 were detected in samples from Tank 103-SY. Other surfactants, including long-chain sulphonates, may be analyzed by ion spray LC/MS (Popenoe et al. 1994).

Analytical support was provided for the Gas Generation Task (Task Leaders Sam Bryan and Larry Pederson). Simulated wastes have been analyzed to determine the extent of component degradation and to identify degradation products. Ion chromatography with conductivity detection was used to determine various degradation products for heating and irradiation experiments of HEDTA. Bryan et al. have provided additional discussions of results in monthly progress reports for the Flammable Gas Safety Program.

\section{References}

Campbell, J. A., S. A. Clauss, K. E. Grant, F.V. Hoopes, B. D. Lemer, R. B. Lucke, G. M. Mong, J. K. Rau, and R. T. Steele. 1994. Flammable Gas Safety Program. Analytical Methods Development: FY . 1993 Progress Report. PNL-9062, Richland, Washington.

Popenoe, D. D., S. J. Morris, III, P. S. Horn, and K. T. Norwood. 1994. Determination of Alkyl Sulfates and Alkyl Ethoxysulfates in Wastewater Treatment Plant Influents and Effluents and in River Water Using Liquid Chromatography/Ion Spray Mass Spectrometry. Anal. Chem., 66, 1620-1629.

Rice, A.D. 1995. 216-Day Final Report for Tank 241-SY-103, Push Mode-Core 62. WHC-SD-WMDP-074, Rev.0, Westinghouse Hanford Company, Richland, Washington. 



\section{Glossary}

$\mathrm{BF}_{3} \quad$ boron trifluoride

CA citric acid

ED3A ethylenediaminetriacetic acid

EDTA ethylenediaminetetraacetic acid

GC/MS gas chromatography/mass spectrometry

HEDTA N-(2-hydroxyethyl)ethylenediaminetriacetic acid

HPLC high performance liquid chromatography

HRMS high resolution mass spectrometry

IDA iminodiacetic acid

LC liquid chromatography

LC/MS liquid chromatography/mass spectrometry

NED3A n-nitrosoethylenediaminetriacetic acid

NIDA nitrosoiminodiacetic acid

NTA nitrilotriacetic acid

NPH normal paraffin hydrocarbons

PFK perfluorokerosene

PFTBA perfluorotributylamine

SA succinic acid

TOC total organic carbon

UV ultraviolet 



\section{Contents}

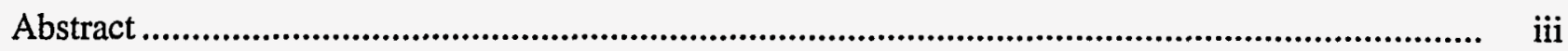

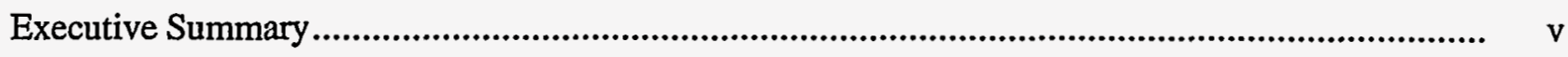

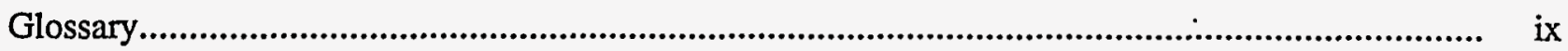

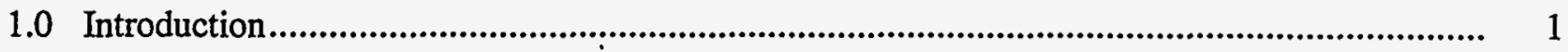

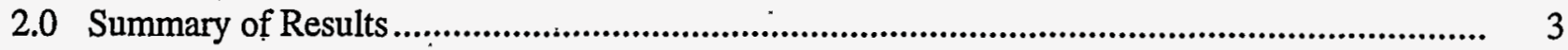

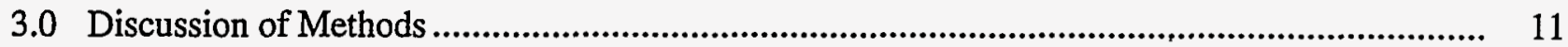

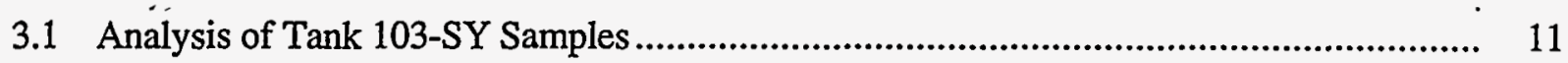

3.2 Tracers for Determining Recoveries ............................................................... 11

3.2.1 Yield Tracers in Chelator Analysis......................................................... 11

3.2.2 Deuterated Chelator Probes................................................................................ 15

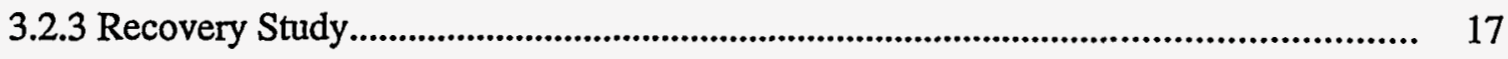

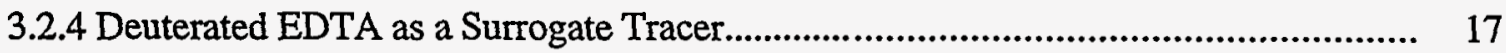

3.3 Cation Exchange for Reduction of Radioactivity Levels................................................. 18

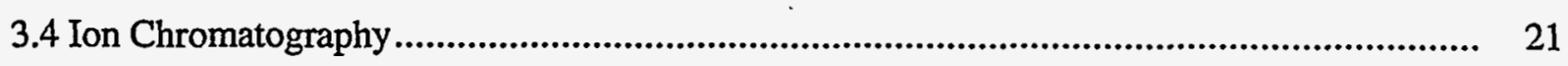

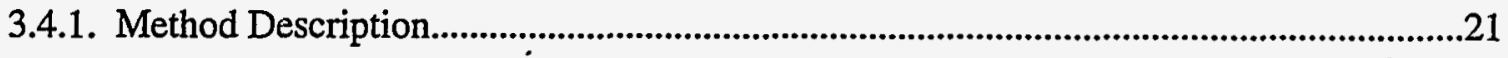

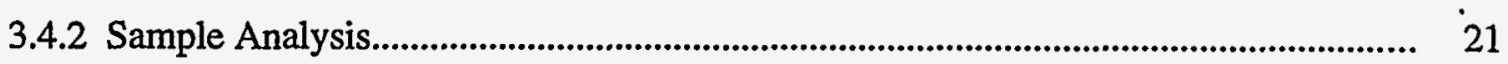

3.5 Nitrate/Nitrite Removal.................................................................................. 28

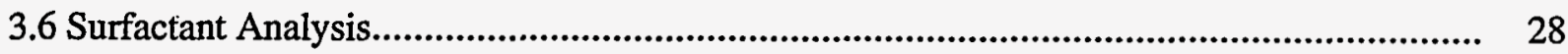

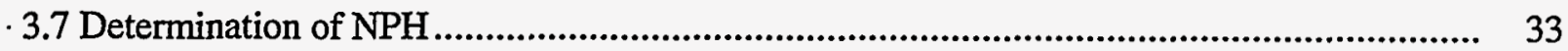

3.8 Chemical Support of Simulated Waste Studies .................................................... 35

3:8.1 Reproducibility ........................................................................................ 35

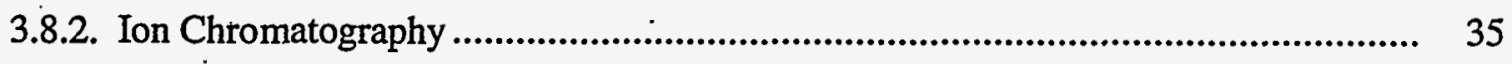

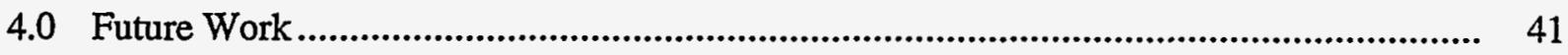

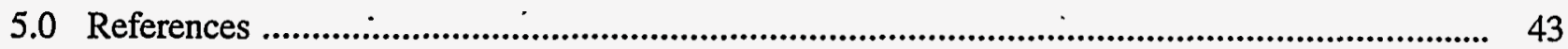

Appendix A - Experimental Procedures............................................................................. A.1 


\section{Figures}

2.1 Schematic of the Sample Preparation and Analysis Scheme ......................................... 6

3.1 Total Ion Chromatogram (GC/MS) of Derivatized Tank 103-SY Sample.............................. 12

3.2 Gas Chromatography/Flame Ionization Detection Chromatogram of

Convective-Layer Sample from Tank 103-SY.

3.3 Gas Chromatography/Flame Ionization Detection Chromatogram of

Nonconvective-Layer Sample from Tank 103-SY

3.4 Total Ion Chromatogram (GC/MS) for Yield Tracer Study .............................................. 16

3.5 Source of the Chelator Fragment from HEDTA of Molecular Weight 288 ........................... 19

3.6 LC Chromatogram for Determination of Oxalate........................................................ 22

3.7 LC Chromatogram for Determination of Acetic, Glycolic, and Formic Acids........................ 23

3.8 LC Chromatogram of Low-Molecular Weight Acids with UV Detection .............................. 24

3.9 Chromatogram of Low-Molecular Weight Acids with UV Detection in Simulated

Waste Sample............................................................................................................ 25

3.10 Ion Chromatography Chromatogram of an Organic Acids Standard................................... 26

3.11 Ion Chromatography Chromatogram of a Simulated Waste Using Conductivity Detection ....... 27

3.12 Total Ion Chromatogram (GC/MS) of a Concentrated, Derivatized Nonconvective Layer Sample from Tank 103-SY .....................................................................................

3.13 Identification of Stearic Acid (C18) in the Total Ion Chromatogram............................... 30

3.14 Total Ion Chromatogram (GC/MS) of Derivatized Eicosanoic Acid (C20) ............................. 31

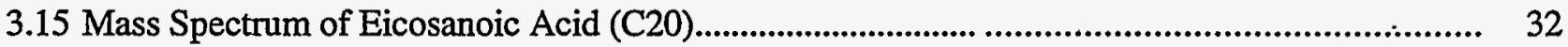

3.16 Total Ion Chromatogram (GC/MS) of the Chloroform Extract of Sample from Tank 101-SY.... 33

3.17 Total Ion Chromatogram (GC/MS) of Chloroform Extract of Sample from Tank 103-SY ......... 34

3.18 Ion Chromatography Chromatogram of Inorganic Simulant Spiked with HEDTA................... 37

3.19 Ion Ch;romatography Chromatogram of Degradation Products of HEDTA in the Solids........... 38

3.20 Ion Chromatography Chromatogram of Degradation Products of HEDTA in Supernate............ 39 


\section{Tables}

S.1 Carbon Accounted for by Chelators, Chelator Fragments, Low Molecular Weight Acids, and Normal Paraffin Hydrocarbon in Tank 103-SY Convective and Nonconvective-Layer Samples. vi

S.2 Carbon (TOC) Accounted for by Chelators, Chelator Fragments, Low

Molecular Weight Acids, and Normal Paraffin Hydrocarbon in

Tank 101-SY Samples (mg C/g)

1.1 Summary of Methods Development and Sample Analysis ................................................. 2

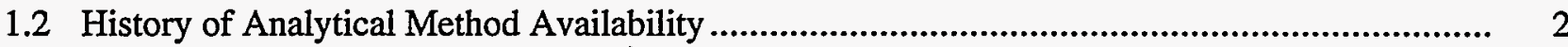

2.1 Summary of Results from Tank 103-SY Samples for Chelator and Chelator Fragment Analysis (mg C/g) Using Derivatization GC/FID.

2.2 Summary of Results from Tank 103-SY Samples for Low Molecular

Weight Acids

2.3 Results of Derivatization GC/MS Analyses on Tank 101-SY Window E Core

Segment Samples-Concentration of Major Components (mg C/g)

2.4 Liquid Chromatography Results for Oxalate, Formic, Glycolic, and Acetic Acids (mg C/g Sample) for 101-SY Window E Core Segment Samples

2.5 Recovery Yield on 101-SY Matrix

2.6 Total Organic Carbon Measurements with Cation Exchange on 101-SY

Samples.

2.7 Results from ${ }^{137} \mathrm{Cs},{ }^{90} \mathrm{Sr}$, and Gross Alpha Analyses in Tank 103-SY Samples

Before and After Use of Cation Exchange for Radioactivity Reduction

2.8 Concentration of Normal Paraffin Hydrocarbon in Tank 101-SY Core

Segment Samples

2.9 Concentration of Normal Paraffin Hydrocarbon in Tank 103-SY Samples.

2.10 Summary of Analyses of Samples from Tanks 101-SY and 103-SY 



\subsection{Introduction}

The objectives of this task are to analyze organic tank wastes to support identification of proposed mechanisms for gas production and to develop and extend organic analysis methods as required. This report documents progress at Pacific Northwest Laboratory (a) during FY 1995 on 1) methods optimization, 2) the analysis of Tank 241-SY-103 (103-SY) waste, 3) total organic carbon (TOC) used as an estimate of organic recovery, 4) recovery studies on samples from Tank 101-SY, 5) further studies of cation exchange resin for the reduction of radionuclides in waste, and 6) use of ion chromatography for the analysis of low-molecular-weight acids in simulated wastes.

Only $10-20 \%$ of the water-soluble organic carbon could be accounted for by derivatization gas chromatography/mass spectrometry (GC/MS) and liquid chromatography (LC) at the beginning of FY 1993, as reported in the FY 1993 Progress Report (Campbell et al. 1994a) delivered to Westinghouse Hanford Company (WHC) on February 1, 1994, All of the sample preparation, including derivatization for chelator analysis, was performed in the hot-cell facilities. At the beginning of FY 1993, a set of eight core segment composite samples of Tank 101-SY from the window E sampling period were being analyzed for chelators, chelator fragments, and carboxylic acids. Four samples were from the convective layer, and four were from the nonconvective layer. Throughout FY 1993, the composite samples were used to refine the analytical methods. The use of simulated wastes was not as beneficial as real wastes for certain methods development; many of the properties of real waste are not duplicated in simulated wastes. Subsamples were used to determine the best sample size to reagent ratio in derivatization GC/MS and to evaluate procedures for removing a major portion of the radioactivity (without loss of organic carbon) to enable the derivatization to be performed in the fume hood: Subsamples were also used to perfect LC methods for low-molecular weight acids. After the analytical procedures were in a final stage of development, additional subsamples of the composite samples were requested from the hot-cell facilities to perform analyses with the refined methods. Unfortunately, the segment composite samples were found to have been inadvertently discarded during a hot- cell cleanup. Additional samples from window $\mathrm{E}$ core sampling were requested from WHC archived samples. These core segments were analyzed using the improved analytical methods, and the results were reported in the FY 1993 Progress Report (Campbell et al. 1994a). Questions regarding the presence or absence of nitroso compounds in the waste samples still remained unanswered at that point.

Efforts in FY 1994 were focused on 1) developing a new sample preparation procedure to include the use of cation exchange for reducing the levels of radioactivity (Campbell et al. 1994b), 2) improve TOC accountability, and 3) verify or refute the existence of nitroso compounds in real waste samples. Removing most of the radioactivity with cation exchange without loss of organic carbon material permitted derivatization in a fume hood. Using a fume hood for sample preparation made it much easier to control the temperature of the reaction and the dryness of the sample; both of these parameters are critical for the derivatization procedures. The fume hood permitted a much smaller sample size to be used for derivatization. This improvement in the method allows the ratio of reagent to sample to be high enough to maximize the recoveries and minimize the matrix effect. The results not only gave much higher concentrations of derivatized components in the samples, but produced analyses that revealed sharp differences in component concentrations with depth in the waste tank. Studies were initiated to determine the radionuclide species removed during the process. In addition, studies were started to compare the sodium and hydrogen forms of the cation-exchange material. A method was developed to identify waterinsoluble organics that may be present in the waste, such as normal paraffin hydrocarbon (NPH). This method involved extracting the basic waste with methylene chloride and subsequent analysis by GC/MS. An LC/MS technique utilizing a basic mobile phase was developed to analyze waste sample to determine whether nitroso compounds existed in the waste or were artifacts of the derivatization procedures. This technique was performed under strictly basic conditions to analyze the samples directly and not under acidic conditions where nitroso compounds can be formed. Results from this study indicate that nitroso

(a) Pacific Northwest Laboratory is operated for the U. S. Department of Energy by Battelle Memorial Institute under Contract DE-AC06-76RLO 1830. 
compounds are formed during the derivatization procedure, a reaction of nitrite in the waste with organic components having an active nitrogen bound to hydrogen such as iminodiacetic acid (IDA) and *. ethylenediaminetriacetic acid (ED3A). The summary of methods development and sample analysis is shown in Table 1.1. Table 1.2 illustrates the chronology of analytical method availability.

During FY 1994, significant progress was made in the amount of TOC accounted for in samples from Tank 101-SY and in analytical methods development. However, problem areas still existed. As a result, efforts in FY 1995 were primarily focused on the application of developed methods to the analysis of samples from Tank 103-SY. Other areas included 1) recovery studies using deuterated internal standards in samples from Tank.101-SY, 2) extension of the application of cation exchange for the reduction of radioactivity levels in samples from Tank 103-SY,3) utilization of ion chromatography for the analysis of low-molecular weight acids in simulants, 5) determination of estimates of reproducibility for the analytical methods, 4) utilization of an analytical technique for the determination of surfactants long-chain carboxylic acids, and 5) analytical support for analyzing simulated and actual wastes for the Gas Generation Task (Sam Bryan- task leader).

This report describes the progress made in FY 1995 in analyzing samples from Tank 103-SY and developing more effective procedures for separating and preparing samples, for isolating and derivatizing components, and for identifying components. These improvements have substantially increased the proportion of organic carbon accounted for by the analytical organic compounds.

Table 1.1. Summary of Methods Development and Sample Analysis

\begin{tabular}{|c|c|c|c|c|c|c|}
\hline Samples & Sample Prep & $\begin{array}{l}\text { Cation. } \\
\text { Exchange }\end{array}$ & $\begin{array}{l}\text { Chelator } \\
\text { Recovery } \\
\end{array}$ & $\begin{array}{l}\text { Derivatization } \\
\text { Yield }\end{array}$ & LMWA & $\begin{array}{c}\text { \%TOC } \\
\text { Accounted For }\end{array}$ \\
\hline $\begin{array}{ll}993 & 101-S Y \\
994 & 101-S Y \\
995 & 103-S Y\end{array}$ & $\begin{array}{l}\text { hot cell }{ }^{(a)} \\
\text { fume hood } \\
\text { fume hood }\end{array}$ & $\begin{array}{l}\text { no } \\
\text { yes } \\
\text { yes }\end{array}$ & $\begin{array}{l}54-60 \% \\
80-90 \% \\
90-95 \%\end{array}$ & $21-115 \%$ & $\begin{array}{l}\text { no } \\
\text { yes } \\
\text { yes }\end{array}$ & $\begin{array}{l}10-20 \\
73-93 \\
51-99^{(\mathrm{c})}\end{array}$ \\
\hline
\end{tabular}

(a) Sample preparation including derivatization performed entirely in hot cell

(b) Derivatization performed in fume hood

(c) Results based on partial data

Table 1.2. History of Analytical Method Availability

$\begin{array}{lll}\text { FY } & \text { Method } & \text { Analytical Focus } \\ 1993 & \text { Derivatization GC/MS } & \begin{array}{l}\text { Chelators and Chelator Fragments } \\ \text { HEDTA,EDTA, NTA, NIDA }\end{array} \\ 1994 & \begin{array}{l}\text { Derivatization GC/MS } \\ \text { LC }\end{array} & \begin{array}{l}\text { Chelators and Chelator Fragments } \\ \text { LMWA-Oxalate, Formate, Acetate } \\ \text { LC/MS }\end{array} \\ \text { Qualitative Determination of LMWA } \\ \text { Derivatization GC/MS } & \begin{array}{l}\text { Qualitative Determination of Chelators } \\ \text { and Chelator Fragments } \\ \text { Quantitative Determination of Chelators } \\ \text { and Chelätor Fragments } \\ \text { Quantitative Determination of LMWA }\end{array} \\ & \text { Derivatization GC/FID } & \\ \text { Ion Chromatography } & \end{array}$




\subsection{Summary of Results and Accomplishments}

The techniques developed and successfully applied to samples from Tank 101-SY were extended to the analysis of convective and nonconvective layer samples from Tank 103-SY. The convective-layer samples were primarily liquid with very little solids present. In contrast, the convective-layer samples from Tank 101-SY contained very little liquid and were primarily solids. The drainable liquids from segments 2-7 were composited to comprise the convective-layer sample from Tank 103-SY. The nonconvective-layer sample was composed of solids from segments 10-14. Total organic carbon (TOC) values were determined by the hot persulfate method for the convective and nonconvective layer samples from Tank 103-SY. The TOC value for the nonconvective layer was $10,500 \mu \mathrm{g} \mathrm{C} / \mathrm{g}$, which was very similar to TOC results from Tank 101-SY. The average value for TOC for the convective layer sample was $6,400 \mu \mathrm{g} \mathrm{C} / \mathrm{g}$. It should be noted that the hot persulfate method is noty a good technique for acetone, butanol, NPH, benzene, and solid hydrocarbons.

Samples from Tank 103-SY have been analyzed for organic constituents. The chelators and chelator fragments were quantified using GC/flame ionization detection. Preliminary results indicate the chelator of highest concentration was EDTA in both convective and nonconvective samples. The concentration of oxalic acid, normally obtained by LC, was determined using GC/flame ionization detection. Preliminary results indicate that oxalic acid is approximately $60 \%$ of the organic carbon in the nonconvective layer sample. Oxalic acid was not detected in the convective-layer sample. In addition, preliminary results indicate that the chelators, chelator fragments, and oxalic acid comprise approximately $80 \%$ of the total organic carbon. The concentration for citric acid is somewhat higher in the convectivelayer sample from Tank 103-SY than 101-SY. Table 2.1 is a summary of the preliminary data for chelator and chelator fragment analyses, and Table 2.2 is a summary of the preliminary data for low-molecular weight acids of samples from Tank 103-SY. The results for low-molecular weight acids are similar to those obtained by the 222-S laboratory (Rice 1995). The data presented here represents results from one sample; replicates will be analyzed. Table 2.3 is a summary of the data from chelator analysis of samples from Tank 101-SY, and Table 2.4 is a summary of the data from low-molecular weight acids analyses of samples from Tank 101-SY (Campbell et al. 1994a) and are included here for comparison. The concentrations of organic components in samples from Tank 101-SY are represented as average values for both the convective and nonconvective layers.

The chelators and chelator fragments comprise $23.4 \%$ and $18.3 \%$ of the TOC in the convective and nonconvective-layer samples from Tank 103-SY, respectively. In contrast, the chelators and chelator fragments constitute $44 \%$ and $26 \%$ of the TOC in convective-layer samples from Tank 101-SY. Lowmolecular weight acids comprise $28.1 \%$ and $80.9 \%$ of the TOC in the convective and nonconvectivelayers samples from Tank 103-SY, respectively. For samples from Tank 101-SY, low-molecular weight acids make up $35 \%$ and $57 \%$ of the convective and nonconvective-layer samples, respectively. The TOC accountability is 78-99\% for the convective and nonconvective-layer samples from Tank 101-SY and the nonconvective-layer sample from Tank 103-SY. At present with limited sample analyses; the TOC accountability for the convective-layer sample from Tank 103-SY is 52\%. Additional samples will be analyzed. Based on preliminary results, there are apparent differences in the concentrations of some of the analytes in samples from Tanks 101-SY and 103-SY. As an example, the concentration of NIDA in the convective-layer sample is approximately five times higher in samples from Tank 101-SY. The concentration of EDTA in the convective-layer sample is approximately 2.5 to 3 times higher than the nonconvective-layer samples from Tank 101-SY. These results are similar to those obtained by Barney with solubility experiments (Barney 1994). However, the EDTA concentrations are practically equal in the convective and nonconvective-layer samples from Tank 103-SY. Additional subsamples will be analyzed to verify Barney's solubility studies (Barney 1994).

Recovery studies on samples from Tank 101-SY using deuterated internal standards were completed in FY 1995. Results of the recovery study by spiking the waste matrix at a level of 3-5 more than estimated to be in the sample showed that, in general, the recovery was nearly quantitative, with the exception of $\mathrm{N}$-(2-hydroxyethyl)ethylenediaminetriacetic acid (HEDTA). Table 2.5 shows the results of the recovery study. The recovery yield obtained for $\mathrm{d}_{4}$ - ethylenediaminetetraacetic acid (EDTA) from the waste matrix suggests that this component could act as an effective surrogate component for determining organic acid loss/dilution error in the sampling and analysis of tank wastes. The observed yield for 
Table 2.1. Summary of Results from Tank 103-SY Samples for Chelator and Chelator Fragment Analysis (mg C/g) Using Derivatization GC/FID

\begin{tabular}{|c|c|c|c|c|c|c|c|c|c|}
\hline imple & NIDA & NTA & $\mathrm{CA}$ & $\mathrm{ED} \mathrm{A}^{(\mathrm{b})}$ & EDTA & $\mathrm{HEDTA}^{(\mathrm{c})}$ & $\underline{\mathrm{SA}}$ & $\begin{array}{c}\text { TOC } \\
\text { Accounted For } \\
\text { (d) }\end{array}$ & $\begin{array}{c}\% \text { TOC } \\
\text { Accounted For } \\
\end{array}$ \\
\hline & 0.16 & $\begin{array}{l}0.14 \\
0.16\end{array}$ & $\begin{array}{l}0.42 \\
0.56\end{array}$ & $\begin{array}{l}0.25 \\
0.16\end{array}$ & $\begin{array}{l}0.55 \\
0.65\end{array}$ & 0.03 & $\begin{array}{r}0.02 \\
0.02\end{array}$ & $\begin{array}{l}1.49 \\
1.71\end{array}$ & $18.2 \%$ \\
\hline
\end{tabular}

Table 2.2. Summary of Results (mg C/g)from Tank 103-SY Samples for Low-Molecular-Weight Acids

\begin{tabular}{|c|c|c|c|c|c|c|}
\hline Sample & Oxalic & Glycolic & Acetic & Formic & Total & $\begin{array}{c}\% \text { TOC } \\
\text { Accounted For }\end{array}$ \\
\hline $\begin{array}{l}\mathrm{C} \\
\mathrm{NC}\end{array}$ & 6.0 . & & $\begin{array}{l}0.6 \\
0.7\end{array}$ & $\begin{array}{l}1.2 \\
0.9\end{array}$ & $\begin{array}{l}1.8 \\
7.6\end{array}$ & $\begin{array}{l}28.1 \\
80.9\end{array}$ \\
\hline
\end{tabular}

NC Nonconvective

C Convective

Table 2.3. Results of Derivatization ${ }^{\text {(a) }}$ GC/MS Analyses on Tank 101-SY Window E Core Segment Samples Concentration of Major Components (mg C/g Sample)

\begin{tabular}{|c|c|c|c|c|c|c|c|c|c|}
\hline Sample & NIDA & NTA & $\underline{\mathrm{CA}}$ & $\underline{E_{3} A^{(b)}}$ & $\underline{\text { EDTA }}$ & $\mathrm{HEDTA}^{(\mathrm{c})}$ & $\underline{\mathrm{SA}}$ & $\begin{array}{c}\text { TOC } \\
\text { Accounted For }^{(\mathrm{d})} \\
\end{array}$ & $\begin{array}{c}\% \text { TOC } \\
\text { Accounted } \\
\end{array}$ \\
\hline $\begin{array}{l}\mathrm{C} \\
\mathrm{NC}\end{array}$ & $\begin{array}{l}1.04 \\
0.82\end{array}$ & $\begin{array}{c}0.33 \\
0.22\end{array}$ & $\begin{array}{l}0.32 \\
0.31\end{array}$ & $\begin{array}{l}0.30 \\
0.28\end{array}$ & $\begin{array}{l}2.23 \\
0.80\end{array}$ & - & $\begin{array}{l}0.07 \\
0.05\end{array}$ & $\begin{array}{l}4.9 \\
2.9\end{array}$ & 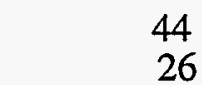 \\
\hline
\end{tabular}

(a) Derivatization performed in fume hood

(b) Assuming response similar to EDTA

(c) . HEDTA was found in window E composite samples, but not in the segment subsamples.

(d) Total includes minor components not included in this summary table.

C Convective layer

NC Nonconvective layer

NIDA nitrosoiminodiacetic acid

NTA nitrilotriacetic acid

CA citric acid

ED3A ethylenediaminetriacetic acid

EDTA ethylenediaminetetraacetic acid

HEDTA N-(2-hydroxyethyl)ethylenediaminetriacetic acid

SA succinic acid 
Table 2.4. LC Results for Oxalate, Formic, Glycolic, and Acetic Acids (mg C/g Sample) for 101-SY Window E Core Segment Samples

\begin{tabular}{|c|c|c|c|c|c|c|}
\hline Sample & Oxalic & Glycolic & Acetic & Formic & Total & $\begin{array}{c}\% \text { TOC } \\
\text { Accounted For }\end{array}$ \\
\hline C & 1.8 & 0.54 & & 1.4 & 3.7 & 35 \\
\hline *R4259/C & 2.0 & 0.43 & 0.81 & 1.4 & 4.5 & 44 \\
\hline $\mathrm{NC}$ & 5.7 & nd & nd & 0.62 & 6.3 & 57 \\
\hline
\end{tabular}

C Convective layer

NC Nonconvective layer

* Represents only convective-layer sample with acetate

Table 2.5. Spike Recovery Yields on 101-SY Matrix

\begin{tabular}{|c|c|}
\hline Target Compound & Yield $(\%)$ \\
\hline Succinic Acid & 101 \\
\hline Citric Acid & 108 \\
\hline NTA & 111 \\
\hline EDTA & 117 \\
\hline d4-EDTA & 85 \\
\hline HEDTA & 27 \\
\hline
\end{tabular}

HEDTA was approximately $30 \%$. The sensitivity or response factor of methylated-HEDTA was substantially lower than that of EDTA or nitrilotriacetic acid (NTA), 70\% less on a molar basis. This discrepancy was resolved by analyzing a sample of methylated-HEDTA using direct probe/MS. Trimethylated-HEDTA, with an unreacted, or free, hydroxyethyl group, accounted for the remaining $70 \%$ of the derivatized HEDTA. It has been postulated that this species is simply too polar to migrate through the GC column. To determine whether the methylated-HEDTA was sorbed onto the GC column, two experiments were performed. In the first, HEDTA was silylated, and the product was analyzed using MS and GC/MS. A single species, tetramethylsilyl ester of HEDTA, chromatographed as a single GC peak. As a second test, methylated-HEDTA was silylated. The reaction product was then analyzed using MS and GC/MS. Two species were identified as two distinct GC peaks; the results indicate that the underivatized hydroxyethyl group of HEDTA rendered any such derivative too polar to migrate through the GC column.

A new sample preparation procedure has been developed that resulted in a better accounting for the organic carbon. A 5-g aliquot of tank waste is stirred overnight with $10 \mathrm{~mL}$ of water. The filtered aqueous solution is then passed through a bed of cation-exchange resin and rinsed with $10 \mathrm{~mL}$ of water. All of the above steps are performed in the hot cell, and the resulting solution is sufficiently low in activity to allow removal to a fume hood. An aliquot is concentrated to dryness under a stream of nitrogen. The dry material is derivatized with boron trifluoride $\left(\mathrm{BF}_{3}\right) /$ methanol, and the derivatized material, in chloroform, contains less than $1 \%$ of the original radioactivity. It can then be analyzed by GC/MS for derivatized components. The sample preparation and analysis scheme is shown schematically in Figure 2.1.

Removal of most of the radioactivity with cation exchange without loss of organic carbon material permitted derivatization to be performed in a fume hood. Table 2.6 shows the results from studies of the cation exchange material with samples from Tank 101-SY. Similar results were obtained samples from Tank 103-SY. For the nonconvective-layer samples, The TOC value obtained prior to cation exchange was $9400 \mu \mathrm{g} \mathrm{C} / \mathrm{g}$ and after was $8500 \mu \mathrm{g} \mathrm{C} / \mathrm{g}$. The values of TOC obtained from the convective-layer samples are somewhat confusing. If the original sample contained small amounts of 


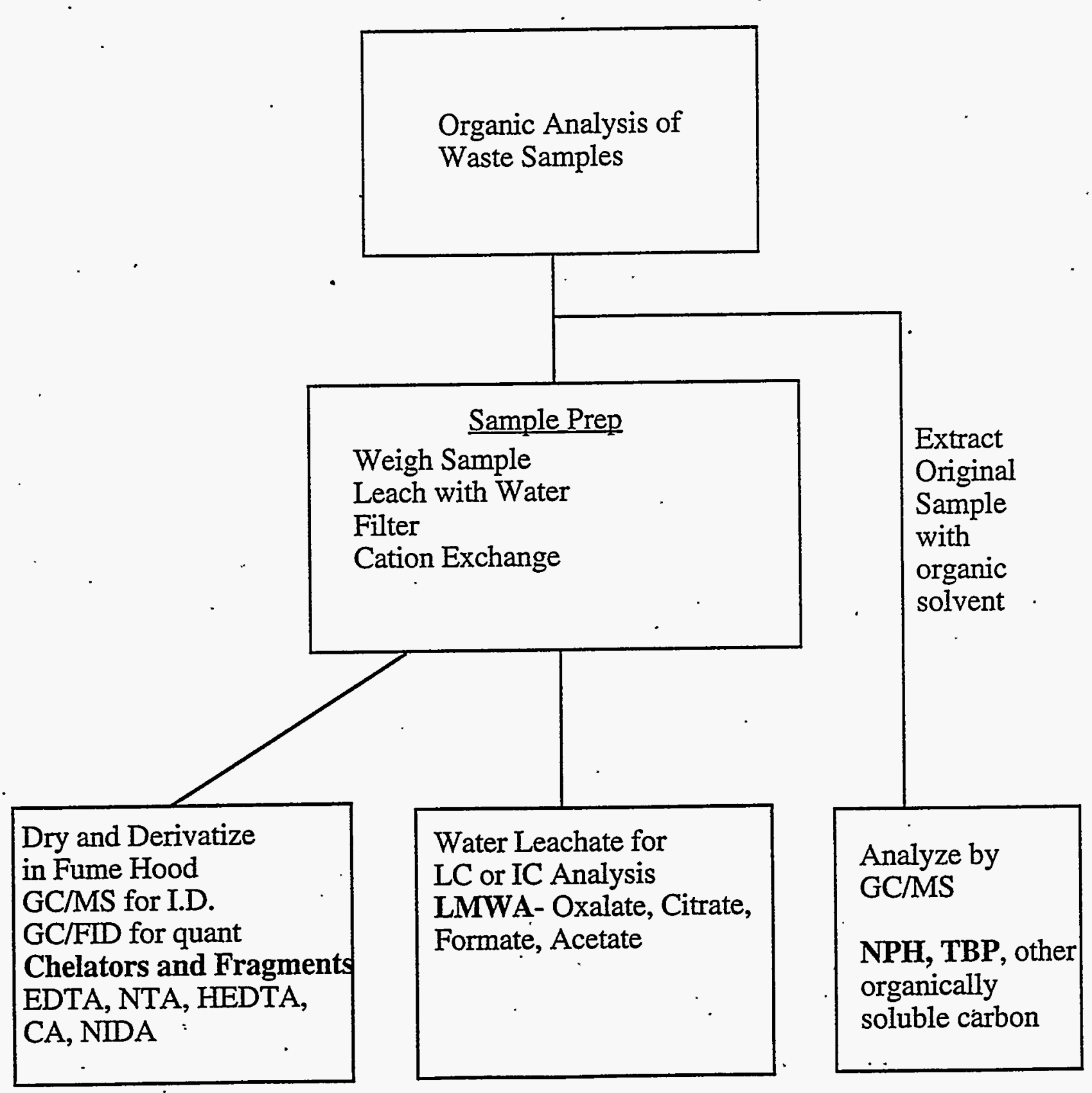

Figure 2.1. Schematic of the Sample Preparation and Analysis Scheme 
Table 2.6. TOC Measurements With Cation Exchange

Sample

$\begin{array}{lcc} & \text { Trial \#1 } & \text { Trial \#2 } \\ & & \\ \text { Waste Sample } & 2100 & 1995 \\ \text { After sepn thru } \mathrm{Na}^{+} \text {form } & 2200 & 2170 \\ \text { After } \mathrm{H}^{+} \text {form } & 470 & 490 \\ \text { Blank } \mathrm{H}^{+} \text {form } & 9.5 & 8 \\ \text { Blank } \mathrm{Na}^{+} \text {form } & <0.5 & <0.5\end{array}$

sludge, the TOC numbers might be much higher than after the cation exchange. Further experimentation is underway with the convective layer to determine if any TOC is lost. Using a fume hood for sample preparation made it much easier to control the temperature of the reaction and the dryness of the sample; both of these parameters are critical for the derivatization procedures. The fume hood permitted use of a much smaller sample size for derivatization. This improvement in the method allows the ratio of reagent to sample to be high enough to maximize the recoveries and minimize the matrix effect. The results not only gave much higher concentrations of derivatized components in the samples, but produced analyses that revealed sharp differences in component concentrations with depth in the waste tank. Analysis of samples from Tank 103-SY showed that the radioactivity level of ${ }^{137} \mathrm{Cs}$ was reduced by a factor of approximately 300 , and the level of ${ }^{90} \mathrm{Sr}$ was reduced by a factor of $10-15$. The results are shown in Table 2.7.

Liquid chromatography with UV detection was previously used for the analysis of low-molecular weight acids. High concentrations of nitrate and nitrite interfered with quantitating citrate, succinate, and glycolate. To quantify organic acids, two procedures were required. For oxalic acid, a basic mobile phase was required. For acetic, formic, and glycolic acids, an acidic mobile phase was used. Dilution of the sample was not a viable option due to the relative insensitivity of detection by UV for organic acids. Alternatively, analysis for combined organic carboxylates in the presence of tank simulant matrix is possible using ion chromatography with a gradient elution profile and suppressed conductivity detection. Ion chromatography has been developed and has provided a single, faster, and cheaper method for analyzing low-molecular weight acids, practically free of matrix interferences. This method has been successfully applied to studies of simulated wastes and will be extended to real-waste analysis.

Because nitrite and nitrate were primary interferences in the analysis of low-molecular weight acids, two tactics were explored for removing these components from a simulant matrix. Solid phase extraction was examined as a prospective method to trap some of the low-molecular weight acids components from the matrix material as carboxylic acids. This requires that the samples be acidified and introduced through the support media, with the neutral organics remaining on the column. The other method utilized sulfamic acid to convert nitrite to nitrogen gas, thus relieving the matrix of this material. The problematic aspects of the two treatments is the necessity to acidify the matrix, which leads to concomitant production of nitrous acid and nitroso compounds. At this point, a separation using ion chromatogrpahy was a distinct advantage over both of these pretreatments.

Derivatization using $\mathrm{BF}_{3}$ /methanol for analyzing long-chain carboxylic acids using derivatization GC/MS. The reaction forms the methyl esters of the carboxylic acids. This method is the same method used for analyzing chelators and chelator fragments. Standards of C18 and C20 were analyzed by GC/MS. In instances where no parent ion is evident by electron impact MS, chemical ionization MS can be used to verify the molecular weight. In addition, very low concentrations of C16 and C18 were identified in waste from Tank 103-SY. Other types of surfactants (long-chain sulphonates) may be analyzed using ion spray LC/MS (Popenoe et al. 1994). 
Table 2.7. Results from ${ }^{137} \mathrm{Cs},{ }^{90} \mathrm{Sr}$, and Gross Alpha Analyses in Tank 103-SY Samples Before and After Use of Cation Exchange for Radioactivity Reduction

$\begin{array}{lccll}\text { Sample } & \text { Isotope } & \text { Before }(\mu \mathrm{Ci} / \mathrm{g}) & & \text { After }(\mu \mathrm{Ci} / \mathrm{g}) \\ \text { Nonconyective } & { }^{137} \mathrm{Cs} & 260.80 & 0.29 \\ & { }^{90} \mathrm{Sr} & 4.75 & 0.033 \\ \text { Convective } & \text { gross alpha } & { }^{137} \mathrm{Cs} & 0.002 & 0.0000143 \\ & { }^{90} \mathrm{Sr} & 273.00 & 1.23 \\ & \text { gross alpha } & 6.92 & 0.55 \\ & & 0.007 & 0.0000061\end{array}$

Table 2.8 shows the concentration of normal paraffin hydrocarbon (NPH) in samples from Tank 103-SY. This represents only partial data. Additional samples will be analyzed. Normal paraffin hydrocarbon was also identified in chloroform extracts of Tank 101-SY waste samples; the concentrations varied from 20-1440 ppm. The concentration of NPH varies with depth of the sample as expected, Table 2.9 shows the concentration of NPH found in Tank 101-SY waste samples (Campbell et al. 1994b). Comparison of all the analytical results from Tank 103-SY and 101-SY samples are shown in Table 2.10.

Some aspects of sample result variability and uncertaintly were assessed. The reproducibility of the results from derivatization GC with subsequent quantitation using MS was estimated to be approximately $10 \%$ from duplicate manual injections of the same sample. Sub-sample variation was estimated to be approximately 14-20\%, depending on the component. Variability in sample analysis using $\mathrm{GC} /$ flame ionization detection for quantitation was approximately $5 \%$. As a result, GC/flame ionization detection will be used for quantification and GC/MS will be used for identification of organic components in future waste samples. Recovery of oxalic acid from spikes in a simulated waste was $91 \%$. The reproducibility for the LC measurements of oxalic acid was estimated to be $5 \%$. The determination of the other small acids was estimated to be approximately $10 \%$, due to baseline drift. The variability from sample to sample was a combination of sample heterogeneity and analytical irreproducibility.

Analytical support was provided for the analysis of simulated wastes for the Gas Generation Task (Sam Bryan -Task Leader). Ion chromatography was developed and used to identify degradation products of heated and heated, irradiated waste samples containing HEDTA.

Table 2.8. Concentration of Normal Paraffin Hydrocarbon in Tank 103-SY Samples

Sample

Convective

Nonconvective
$\underline{\mathrm{NPH}}$

tbd

tbd

tbd $=$ to be determined 
Table 2.9. Concentration (PPM) of Normal Paraffin Hydrocarbon in Tank 101-SY Core Segment Samples

\begin{tabular}{|c|c|c|}
\hline Sample & Segment \# & NPH \\
\hline $\begin{array}{l}\text { R4258 } \\
\text { R4259(a) }\end{array}$ & $\begin{array}{l}4 \\
6\end{array}$ & 1440 \\
\hline R4260 & 9 & 410 \\
\hline R4261 & 11 & 670 \\
\hline R4262 & 16 & 0 \\
\hline $\mathrm{R} 4263^{(\mathrm{a})}$ & 17 & \\
\hline
\end{tabular}

(a) Insufficient sample remaining to determine concentration of NPH.

Table 2.10. Summary of Anälyses of Samples from Tanks 101-SY and 103-SY

\begin{tabular}{|c|c|c|c|c|}
\hline Analyte & $\begin{array}{l}\text { 101-SY } \\
\text { Convective }\end{array}$ & $\begin{array}{l}103-S Y^{(a)} \\
\text { Convective }\end{array}$ & $\begin{array}{l}101-S Y \\
\text { Nonconvective }\end{array}$ & $\begin{array}{l}\text { 103-SY } \\
\text { Nonconvective }\end{array}$ \\
\hline NIDA & 1.04 & 0.20 & 0.82 & 0.16 \\
\hline NTA & 0.33 & 0.14 & 0.22 & 0.16 \\
\hline CA & 0.32 & 0.42 & 0.31 & 0.56 \\
\hline ED3A & 0.30 & 0.25 & 0.28 & 0.16 \\
\hline EDTA & 2.23 & 0.55 & 0.80 & 0.65 \\
\hline HEDTA & nd & 0.03 & nd & nd \\
\hline $\mathrm{SA}$ & 0.07 & 0.02 & 0.05 & 0.02 \\
\hline Oxalate & 1.90 & nd & 5.70 & 6.00 \\
\hline Glycolate & 0.48 & tbd & nd & tbd \\
\hline Formate & 1.40 & 1.20 & 0.62 & 0.90 \\
\hline Acetate & 0.81 & 0.60 & nd & 0.70 \\
\hline $\mathrm{NPH}^{(b)}$ & 800.00 & tbd & 20.00 & tbd \\
\hline $\mathrm{OH}$ & 25,000 & $28,600^{(\mathfrak{c})}$ & 25,000 & $15,000^{(\mathrm{d})}$ \\
\hline
\end{tabular}

(a) Based on limited sample analyses

(b) ppm

(c) $\mu \mathrm{g} / \mathrm{mL}$

(d) $\mu \mathrm{g} / \mathrm{g}$

nd not detected

tbd to be determined . 



\subsection{Discussion of Methods}

\subsection{Analysis of Tank 103-SY Samples}

\section{GC/MS and LC}

The techniques of derivatization GC/MS and LC are used to provide data on the speciation of organic components as well as functional groups (Grant et al. 1995a,b)

\section{GC/MS}

The chelators and chelator fragments represent a class of compounds whose polarity and nonvolatility precludes direct analysis by GC/MS; therefore, derivatization of the carboxylic acid portion must be performed before analysis. Chelators, chelator fragments, and several carboxylic acids have been quantitated in the convective and nonconvective layer samples from Tank 103-SY using derivatization GC/flame ionization detection. The samples were also analyzed using GC/MS to identify unknown components. The major components detected were EDTA, NIDA, nitrilotriacetic acid (NTA), citric acid (CA), succinic acid (SA), and ED3A. Preliminary results indicate the chelator of highest concentration was EDTA in both layers. However, the concentration of citric acid was nearly the same as EDTA. The data reported is the result of analysis of one sample from both the convective and nonconvective layers. Additional samples must be analyzed to 1 ) determine the accuracy and precision for GC/flame ionization detection as a quantitation technique and 2) verify concentrations of EDTA and citric acid in both the convective and nonconvective-layer samples and compare with Barney's solubility results (Barney 1994). A total ion chromatogram of a derivatized sample from Tank 103-SY is shown in Figure 3.1, and $\mathrm{GC} /$ flame ionization detection chromatograms of the convective and nonconvective layer-samples are shown in Figures 3.2 and 3.3, respectively.

\section{$\underline{\mathrm{LC}}$}

Liquid chromatography has been used to quantitate low-molecular weight acids (oxalic, formic, glycolic, and acetic acids, which are present in the waste as acid salts) in samples from Tanks 101-SY and 103-SY. The concentration of acetate and formate in the convective-layer sample from Tank 103-SY were 1.6 and $4.4 \mathrm{mg} / \mathrm{g}$, respectively. These results are very similar to those obtained by the 222-S laboratory (Rice 1995). Acetic and formic acids amount to approximately $28.1 \%$ of the TOC in the convective-layer sample. For the nonconvective-layer sample, oxalic, acetic, andformic acids constitute approximaely $81 \%$ of the TOC. Approximately 23 to $61 \%$ of the TOC is accounted for by these acids in samples from Tank 101-SY. Oxalic acid constitutes approximately $40 \%$ of the TOC in the nonconvective layer samples from Tank 101-SY. The concentration of oxalate in the nonconvective layer is approximately 3 to 4 times higher than the convective layer: The nonconvective layer sample from the lowest layer has the highest percentage of water-soluble organic carbon as low-molecular weight acids.

\subsection{Tracers for Determining Recoveries}

\subsubsection{Yield Tracers in Chelator Analysis}

Recovery studies were performed using samples from Tank 101-SY. Of the available reagents, only $\mathrm{BF}_{3}$-methanol has been shown to give reliable derivatization with chelator materials contained in tank wastes. Even powerful methylating reagents such as dimsyl anion - $\mathrm{CH}_{3} \mathrm{I}$ and diazomethane do not provide usable yields of the corresponding methyl esters of EDTA and NTA. 


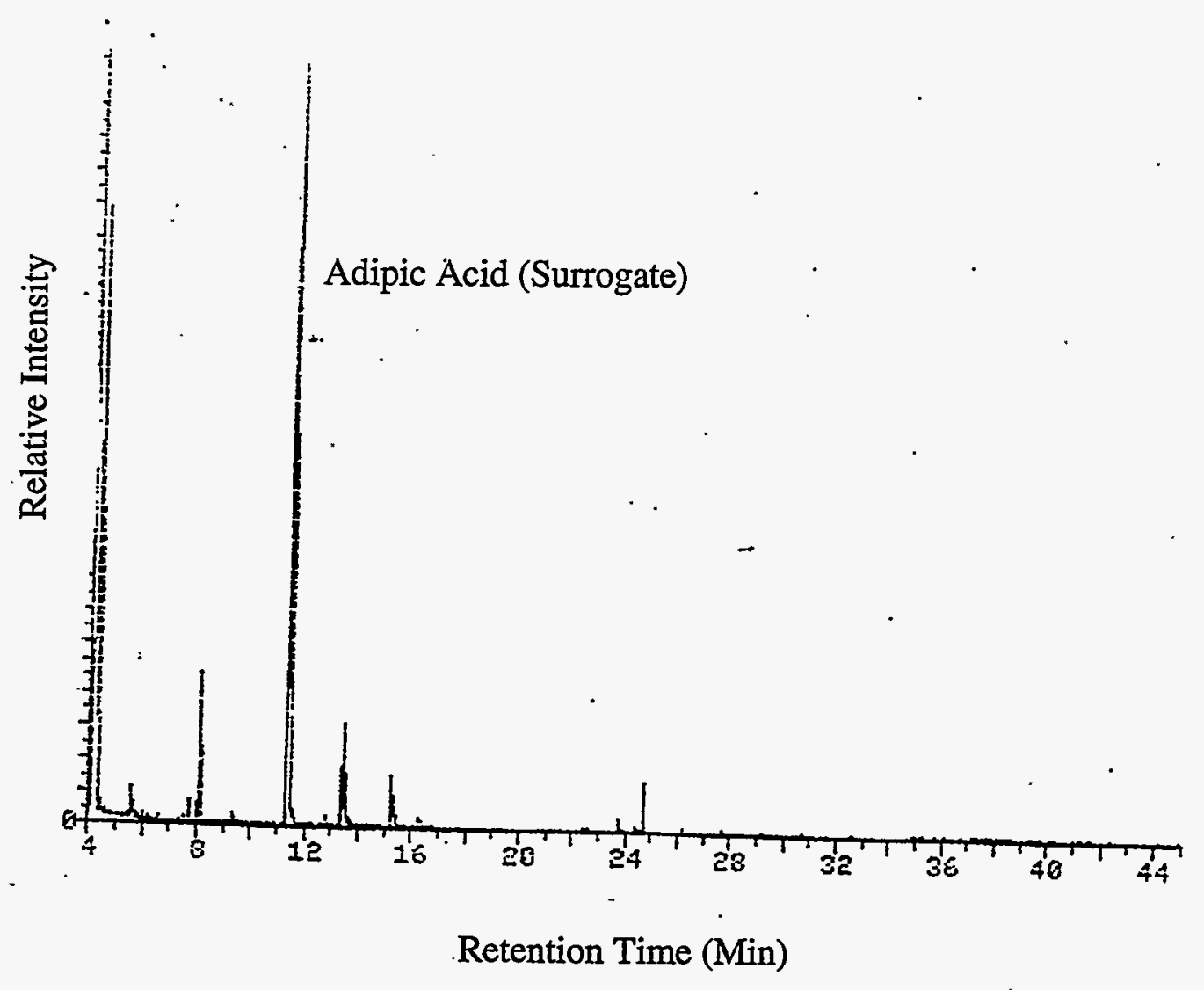

Figure 3.1. Total Ion Chromatogram (GC/MS) of Derivatized Tank 103-SY Sample 


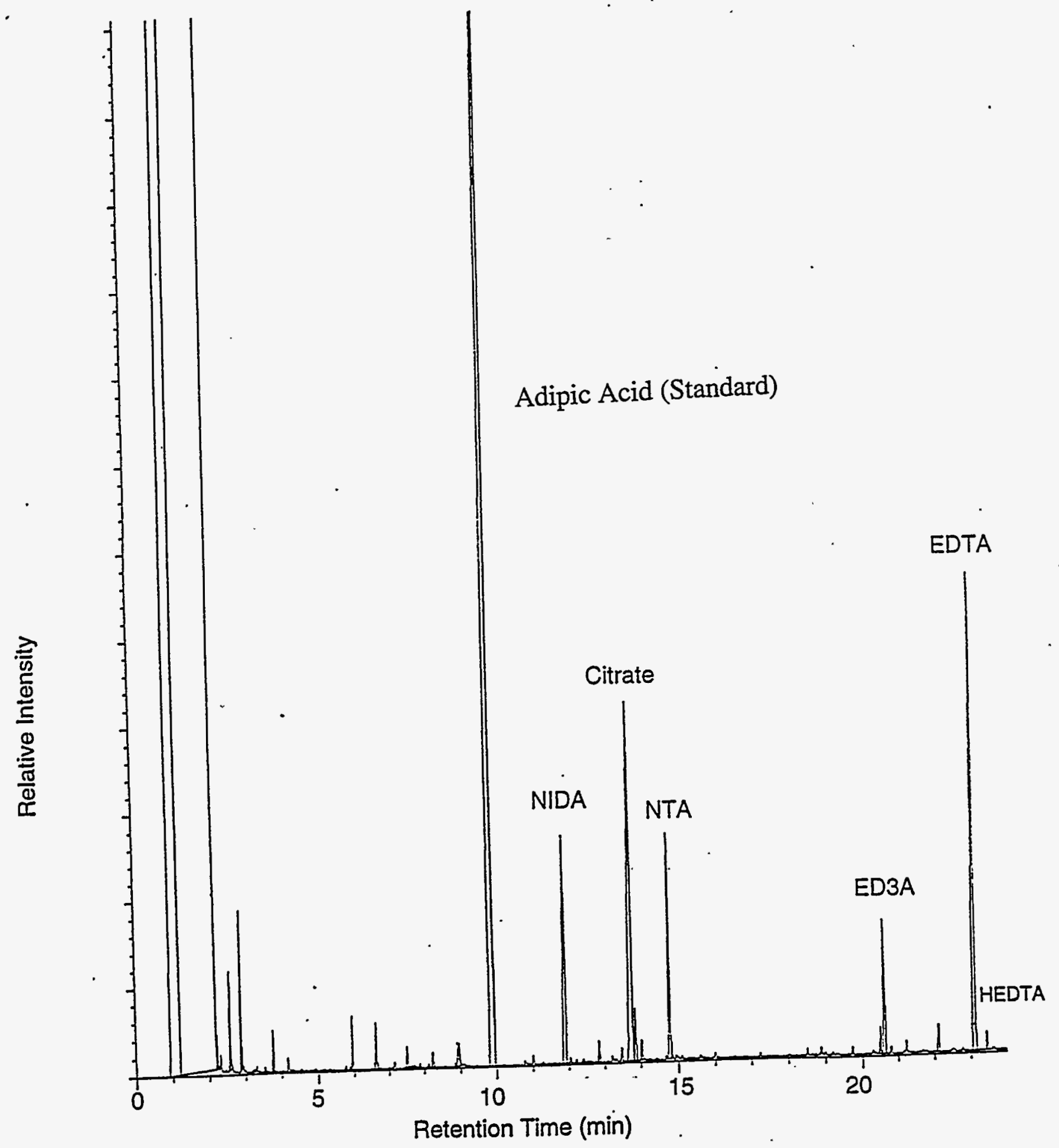

Figure 3.2. Gas Chromatography/Flame Ionization Detection Chromatogram of Convective-Layer Sample from Tank 103-SY 


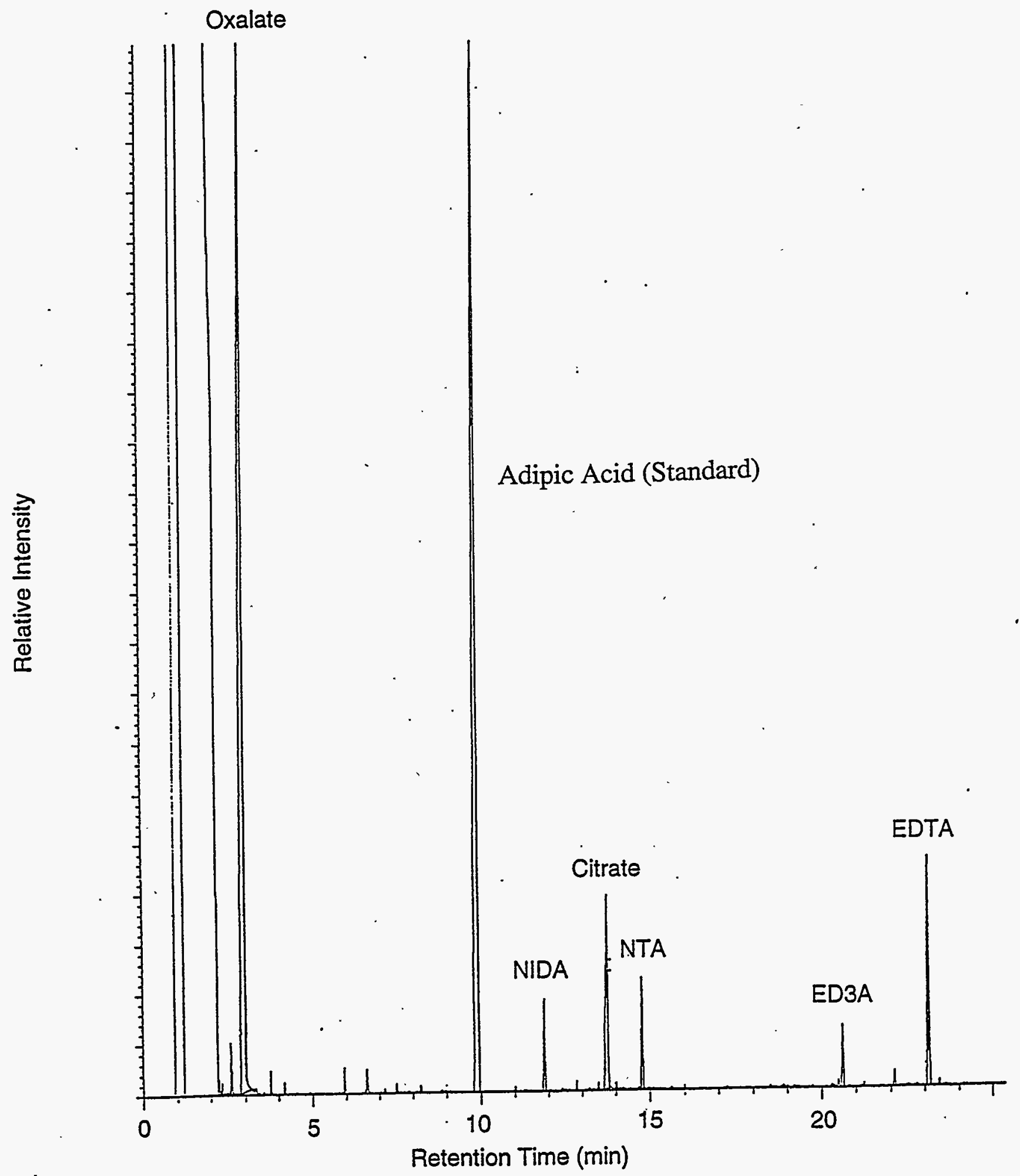

Figure 3.3. Gas Chromatography/Flame Ionization Detection Chromatogram of Nonconvective-Layer Sample from Tank 103-SY 
Results to quantify the relative amounts of chelators present in Hanford wastes versus the amount of carbon apparent in TOC analysis have been reported (Campbell et al. 1994b). However, the amount of conversion of these materials to methyl esters using Hanford tank matrix was quantified to determine speciesaccountability. Initially, the direction taken to probe the overall yield from the $\mathrm{BF}_{3}$-methanol esterification was to add a known quantity of aliphatic mono-carboxylic acid to the matrix and quantify the result obtained from this experiment for the aliphatic acid versus the result obtained from a separate derivatization using reagent acids as their respective sodium salts. For this probe to be useful, the aliphatic acid chosen must not interfere with the chromatography of the known chelators and chelator fragments found in the matrix. The first candidate tested for this application was myristic acid $\left(\mathrm{C}_{13} \mathrm{H}_{27} \mathrm{COOH}\right)$, the methyl ester of which eluted beyond that of NTA and before the methyl esters of ED3A and EDTA. A representative chromatogram is shown in Figure 3.4., with peak 5 being trimethyl NTA, peak 6 as methyl myristate, and peak 7 as tetramethyl EDTA.

Our results indicated that $80-95 \%$ of the myristic acid added to 101-SY matrix in an amount approximately that of the chelators present in the matrix was converted to the methyl ester using $\mathrm{BF}_{3}$ methanol reagent. This number may not be an accurate reflection of the yield for chelators and chelator fragments in the matrix since these materials contain at least two, or as many as four, carboxylic acid sites per molecule and may not be methylated as readily as the singly carboxylated aliphatic acids. Further, steric influences in the case of NTA and EDTA may not allow these materials to methylate as readily as a straight-chain material. The limited solubility of aliphatic acid sodium salts in water may also contribute to loss of the acids in step-wise manipulations involved with the analysis of the matrix. Thus, this material may not possess overall utility in probing conversion yields of chelators in the Hanford tank wastes. Currently, adipic acid (dibasic acid requiring 2 moles of $\mathrm{BF}_{3} /$ methanol) is being explored as a yield tracer for GC/flame ionization detection studies. Being a dibasic acid, this material is more representative of the carboxylates found in the waste mixture. Dimethyl adipate elutes in the GC region before NIDA and not near any of the primary analytes.

\subsubsection{Deuterated Chelator Probes}

Deuterated chelators and/or chelator fragments have a number of distinct advantages over the introduction of other organic acid materials that might be used as yield probes. The methylation chemistry should be identical with that of the ordinary chelator found within the matrix, thus giving a direct measure of the efficiency of the methylation process for that particular chelator. If the labeled material is not subject to deuterium-exchange processes with the highly basic matrix, then the deuterated material can be used as a tracer; added at any point of the process, the probe acts as a monitor for loss of that material during any set of steps. The major criteria for use of these materials involves 1) deuterium stability, 2) well defined amount/response ratios in quantitation, and 3) mass spectrometry (MS) resolution for analysis of particular fragment ions. Unfortunately, the deuterated compounds either co-elute or overlap the parent unlabeled material to some degree. This would present a problem if GC/flame ionization detection were used for quantitation; however, this would not be a problem if GC/MS were used because different ions would be utilized for quantitation.

For initial trials, $d_{4}$-succinic acid was purchased. This material was found to withstand deuterium exchange if added directly to the highly basic SY-101 matrix and derivatized immediately. The $\mathrm{BF}_{3} /$ methanol reagent is a strong Lewis acid, and the reaction produces $\mathrm{HF}$ as a byproduct of reaction. Deuterium exchange on carbons alpha to carbonyl functions is expected to take place upon prolonged contact with base; thus $d_{4}$-succinic acid is likely to suffer from some exchange during contact with the matrix. No H/D exchange was observed in our initial experiments, which was somewhat surprising.

A better probe would not possess exchangeable deuteriums, and an attempt was made to obtain labeled EDTA with the deuteriums on the N-N' bridge carbons. This material was not readily available commercially, and quotes from a manufacturer of labeled materials indicated that purchase would be prohibitively expensive ( $\$ 3000 / \mathrm{g}$, minimum $5-\mathrm{g}$ order). Synthesis of this material was accomplished by the method of Vanyólos (1955) using $d_{4}$-ethylenediamine purchased from Isotech (Miamisburg, Ohio) and sodium chloroacetate. The resulting simple synthesis produces gram quantities of the labeled EDTA in apparent high purity. The bulk synthetic product was analyzed by nuclear magnetic resonance for ${ }^{\prime} \mathrm{H}$. The results displayed only the acetate $\mathrm{H}$ signal, along with a signal corresponding with HOD exchange 


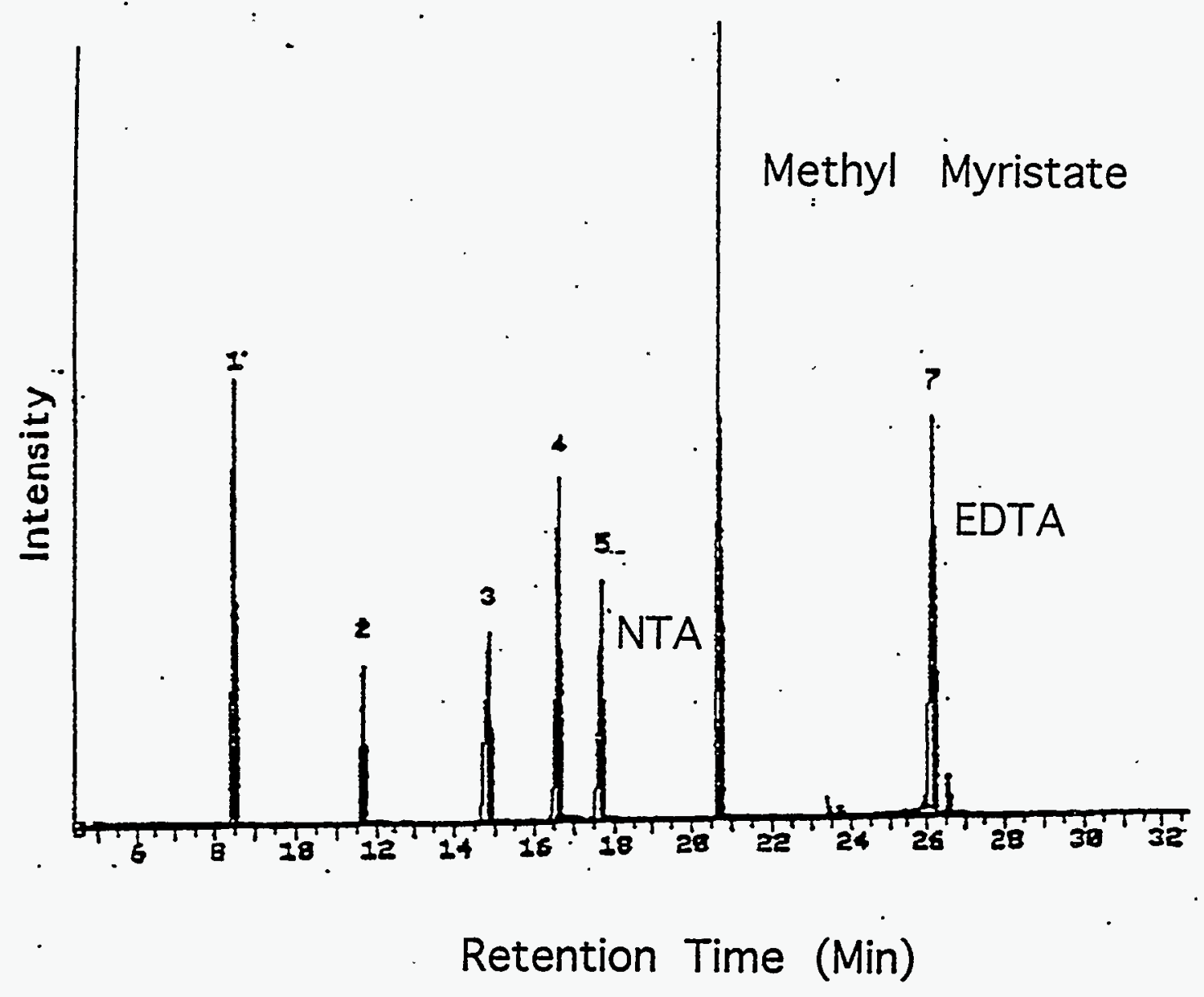

Figure 3.4. Total Ion Chromatogram (GC/MS) for Yield Tracer Study 
from the $\mathrm{D}_{2} \mathrm{O}$ solvent used in the assay. Methylation using $\mathrm{BF}_{3}$-methanol and subsequent GC/MS analysis indicated that the material was essentially free from chelator-type byproducts; however, a trace of thecorresponding ED3A methyl ester was detected. High resolution MS performed with the JEOL High Resolution tandem MS confirmed the expected deuterium content of this material (Campbell et al. 1994a). The structure of the methyl ester is shown below.

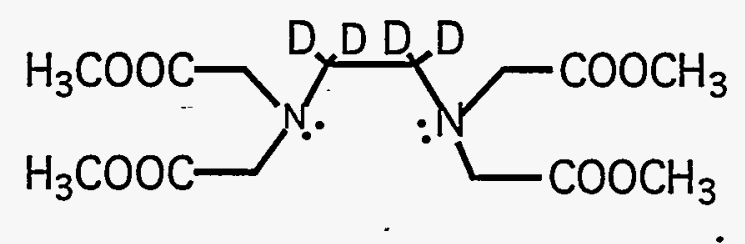

The material produced appears to be essentially pure $\mathrm{d}_{4}$-EDTA. Initial experiments with this material in simulated waste matrices indicates that the deuteriums are not exchanged even when the probe is exposed for long periods to basic media. This material was incorporated into the standard addition recovery study outlined below. The $d_{4}$-EDTA tetramethyl ester was found to practically co-elute with the unlabeled EDTA ester. Consequently, it is only useful when GC/MS is employed for quantitation. Quantification of the two materials should coincide with comparison of corresponding ions for the two compounds at two points in the GOMS trace of the combined eluted peak for the two materials, e.g., comparison of the total amount of ions 174 and 176 at two points in the GC peak. It appears that this will be a very effective probe for total EDTA derivatization in waste matrices.

The other major chelator components in the SY-101 matrix, namely citric acid and NTA, suffer from the potentially exchangeable deuteriums alpha to the carboxyls on the molecule. The suitability of $\mathrm{d}_{4}$-succinic acid as a probe may dictate whether the corresponding deuterated forms of these materials might be pursued as yield probes.

\subsubsection{Recovery Study}

Results of the recovery study by spiking the waste matrix at 3-5 fold more than thought to be in the sample showed that, in general, the recovery was nearly quantitative (See Table 2.5)-with the exception of HEDTA, which has been shown through prior work by Lokken et al. (1986) to undergo only partial conversion to a volatile derivative. Such chemical complexities are often encountered when analyzing chelating agents or their degradation products. In addition, due to the reaction of the matrix with $\mathrm{BF}_{3}$ /methanol, the overall recovery of organics is enhanced by using smaller sample sizes. Usually up to $0.2 \mathrm{~g}$ of waste $/ 2 \mathrm{~mL}$ of $\mathrm{BF}_{3} /$ methanol will give reproducible results.

\subsubsection{Deuterated EDTA as a Surrogate Tracer}

The yield obtained for $d_{4}$-EDTA from the waste matrix (85\%) suggests that this material would act as an effective surrogate component for determining organic acid loss/dilution error in the sampling and analysis of these wastes. To test the ruggedness of this material against deuterium exchange, a sample was. exposed to $2 \mathrm{M}$ aqueous hydroxide overnight, then dried and derivatized with $\mathrm{BF}_{3} /$ methanol in the manner detailed above. The yield of derivatized $\mathrm{d}_{4}$-EDTA and the absence of EDTA or partially deuterated EDTA in the mass spectrum was taken as evidence that the substrate did not readily undergo exchange to the hydroxide matrix or the derivatizing reagent. The overall yield (85\%) is within the expected experimental error and repeatability of the process. The yields for the other components are illustrated in Table 2.5

The observed yield for $\mathrm{N}$-(2-hydroxyethyl) HEDTA was $30 \%$. The sensitivity or response factor of methylated-HEDTA was substantially lower than that of EDTA or nitrilotriacetic acid (NTA), 70\% less on a molar basis. This discrepancy was resolved by analyzing a sample of methylated HEDTA using 
direct probe/MS. The lactone with molecular weight 288 accounted for approximately $30 \%$ of the species detected. Trimethylated HEDTA with an unreacted, or free, hydroxyethyl group accounted for the remaining $70 \%$ of the HEDTA. It is speculated that the species is simply too polar to migrate through the GC columns.

To determine whether the trimethylated HEDTA was sorbed onto the GC column, two experiments were performed. First, HEDTA was silylated, and the product was analyzed using MS and GC/MS. A single species, the tetratrimethylsilyl ether of HEDTA, chromatographed as a single GC peak. As a second test, methylated HEDTA was silylated using the silylating reagents $\mathrm{N}$-bis(trimethylsilyl)acetamine (BSA) and trimethylchlorosilane (TMCS). The reaction product was then analyzed using MS and GC/MS. Two species were identified as two distinct GC peaks: first, the lactone with molecular weight 288 and, second, the mixed derivative of HEDTA, the trimethyl ester, mono(trimethylsilyl)ether of HEDTA. This confirmed that the underivatized hydroxyethyl group of . HEDTA rendered any such derivative too polar to migrate through the DB-5 GC column. This is shown in Figure 3.5. Such chemical complexities are often encountered when analyzing chelating agents or their degradation products.

\subsection{Cation Exchange for Reduction of Radioactivity Levels}

All of the sample preparation, including derivatization for chelator analysis, was performed in the hot cell facilities in FY 1993. Typically, a 5-g waste sample was stirred with $10 \mathrm{~mL}$ of doubly-distilled water overnight. The solution was filtered through a $0.45 \mu \mathrm{m}$ filter to remove any solid material. The aqueous solution was then dried using nitrogen-blow-down techniques, and the remaining residue was then heated with $2 \mathrm{~mL}$ of $\mathrm{BF}_{3} /$ methanol for $1 \mathrm{~h}$ at $100^{\circ} \mathrm{C}$ to produce the methyl esters of chelators, chelator fragments, and carboxylic acids. After the solution cooled to room temperature, $1 \mathrm{~mL}$ of chloroform was added to the solution, and the entire mixture was added to 3-5 mL of $\mathrm{KH}_{2} \mathrm{PO}_{4}$ adjusted to $\mathrm{pH} 7.0$ with $\mathrm{NaOH}$. The organic layer containing the methyl esters was separated and subsequently analyzed using GC/MS. At that point, only $10-20 \%$ of the TOC could be accounted for.

Radioactivity removal through cation exchange was proven during a liquid chromatographic analysis of a tank-waste sample (Campbell et al. 1994a). A 1-mL aliquot of the water extract from a Tank 101-SY composite sample was diluted and analyzed using LC in a radioactive zone. After the analysis was complete, a counter was used to check for radioactive contamination. The LC column was scanned, and most of the radioactivity was located within the guard column consisting of cation exchange packing material. As a result, a step involving cation exchange to remove the radioactivity was added to the separation procedure. The use of cation exchange resin to remove the radioactivity allowed the samples to be removed from the hot cell to a fume hood; this was probably the single most important step in controlling the dryness of the sample prior to derivatization and heating during the derivatization procedure, which subsequently increased the TOC accounted for.

Initial tests were then performed to determine any losses of HEDTA and EDTA going through the $\mathrm{Na}^{+}$form of the cation exchange column. Preliminary results indicate the recoveries were approximately 90 and $95 \%$, respectively. Further studies are underway to substantiate these numbers. However, if one uses the hydrogen form of the resin, losses of EDTA do occur, presumably due to 


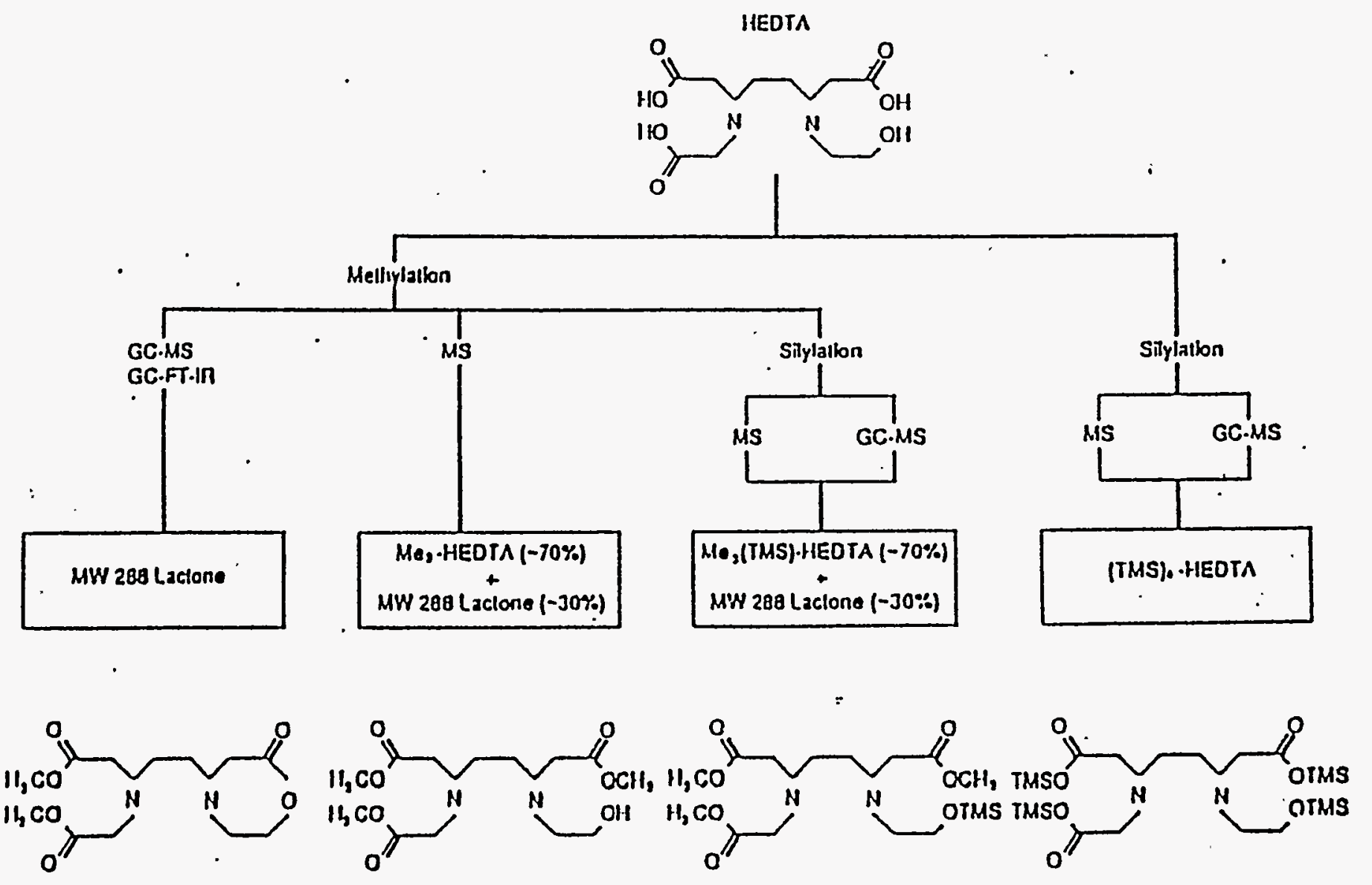

Figure 3.5. Source of the Chelator Fragment from HEDTA of Molecular Weight 288

1 
insolubility of the acid form of EDTA. There may be some loss of TOC due to insoluble EDTA, oxalate, and citrate, but it appears they are minor contributors. Future work may entail recovery studies with citrate, oxalate, and EDTA in simulated matrices to verify the amount of TOC that may be lost with cation exchange.

The current sample preparation method for analysis of core samples of 101-SY and 103-SY for organics is as follows. The TOC of an aliquot is determined on the starting material. A 5-g sample is stirred with $10 \mathrm{~mL}$ of doubly-distilled water overnight. The solution is then filtered through a $0.45-\mu \mathrm{m}$ filter. The TOC is measured on the remaining solid material. The filtered solution is then passed through a preconditioned-Dowex 50 AGX cation exchange resin $\left(\mathrm{Na}^{+}\right.$form, $\left.10 \mathrm{~g}\right)$ and then rinsed with approximately $10 \mathrm{~mL}$ of doubly-distilled water to ensure no soluble organic carbon is left on the column. The radioactivity level of the resulting solution is approximately 200 times less than the original sample. This allows removal of the aqueous sample from the hot cell to perform the derivatizations in the fume hood. The TOC was not changed by passing through the cation exchange column. The material was analyzed for radionuclides after passing through the cation exchange column, and the results indicate it is primarily Cs. However, with the techniques used (Gamma Energy Analysis), Sr would not have been detected. Transferring the derivatization procedure to the fume hood has improved our reproducibility and allows control of the parameters crucial to reproducible results, the temperature and dryness of the sample. The results of TOC accountability from Tank 101-SY core segment samples with incorporation of the cation exchange for radioactive removal are shown in Table 2.6.

To determine if any TOC losses occur through the cation exchange column, TOC values were determined before and after the cation exchange procedure with tank-waste samples. In addition, blanks were also analyzed to determine if any TOC was introduced from the column. The results are shown in Table 2.6 for samples from Tank 101-SY. These results clearly indicate that the cation exchange column $\left(\mathrm{Na}^{+}\right.$form) does not remove or introduce any TOC. This is an extremely important aspect; the sample was not compromised by eluting through the cation exchange resin. Additional studies were undertaken with samples from Tank 103-SY. The TOC value of sludge from Tank 103-SY was $9400 \mu \mathrm{g} \mathrm{C/g}$ prior to cation exchange and an average of $8500 \mu \mathrm{gC} / \mathrm{g}$ after cation exchange.

Analysis of the $103-\mathrm{SY}$ matrix to determine the amount of ${ }^{137} \mathrm{Cs}$ and ${ }^{90} \mathrm{Sr}$ removed by treatment of the sample with AG-50W-X8 cation resin has been completed. For the nonconvective-layer sample, ${ }^{137} \mathrm{Cs}$ was reduced by a factor of approximately 900 . The ${ }^{90} \mathrm{Sr}$ level was reduced by 150 , and gross alpha was reduced by a factor of approximately 1,400 . The level of ${ }^{137} \mathrm{Cs}$ was reduced by a factor of $222,{ }^{90} \mathrm{Sr}$ was . reduced by a factor of 13, and the gross alpha was reduced by a factor of approximately 1200 for the convective-layer sample. The apparent difference ${ }^{90} \mathrm{Sr}$ removal between the convective and nonconvective-layer samples may reflect the degree of $\mathrm{Sr}$ complexation. In other words, the convective layer may contain a higher concentration of complexed Sr. As a result, less Sr would be removed with the use of cation exchange.

The incorporation of the cation exchange step to remove radioactivity was certainly successful in the analysis of samples from Tanks 101-SY and 103-SY. However, the assumption can not be made that it will work for every tank-waste sample. As an example, the results from T-111 samples indicate the loss of carbon going through the cation exchange column. The question at this point is whether it is indeed organic carbon that is lost. Published studies by Baldwin et al. (1994) point out the strengths and weaknesses of the various TOC techniques, which include persulfate, furnace oxidation, and a combination of the two methods. Persulfate determinations may not totally oxidize some types of organic hydrocarbons, and furnace techniques may give erroneously high values due to inorganic carbon. The $\mathrm{pH}$ of the T-111 sample was 9; as a result, the $\mathrm{pH}$ of the sample may be an important variable in using the exchange column for reduction of radioactivity. Further studies are underway to examine this phenomenon. It is recommended that the TOC measurements be made before and after the cation exchange column to ensure the no TOC has been removed or added to the sample. 


\subsection{Ion Chromatography}

\subsubsection{Method Description}

Ion chromatography is an analytical technique for the separation and determination of ionic solutes and falls into the general classification of liquid-solid chromatographic methods, in which a liquid is passed through a solid stationary phase and then to a flow-through detector. The stationary phase is usually in the form of small-diameter, uniform particles packed into a cylindrical column. This column is constructed from a rigid material and is generally $5-30 \mathrm{~cm}$ long, with an internal diameter in the range 4-9 $\mathrm{mm}$. The stationary phase particles are packed uniformly into the column and are retained by means of porous frits located at each end of the column. A high-pressure pump is required to force the eluent through the column at typical flow rates of $1-2 \mathrm{~mL} / \mathrm{min}$. The sample to be separated is introduced into the flowing eluent stream by means of an injection device inserted into the flow path prior to the column. The detector usually contains a low volume cell through which the eluent flows.

The ion-chromatograph is operated in the elution mode. An aliquot of the sample is applied to the top of the column via the injector, while the eluent is passed continuously through the column. The sample components progress through the column at different rates and therefore enter the detector at different times. The detector senses the sample components and produces the chromatograms.

The foundations for modern ion chromatographpy were originally discovered by Small, Stevens, and Bauman in 1975 when they described a novel ion-exchange chromatographic method for the separation and conductimetirc detection of anionic and cationic species (Small et al. 1975). Their method. employed a low-capacity ion-exchange stationary phase for the separation step, together with a second column and conductivity detector that comprised the detection system for continuous monitoring of the eluted ions. The term "ion chromatography" was introduced only when the technology was licensed to the Dionex Corporation for commercial development. For this reason, ion chromatography was originally interpreted to mean the specific use of the same combination of separation and detection modes as reported in the original publication.

The technique of ion chromatography is very loosely defined, both in terms of the manner in which the solutes are separated and the types of solutes applicable to the technique. Ion chromatography typically encompasses those column LC techniques that can be used to determine 1) inorganic anions, 2) inorganic cations, 3) low-molecular-weight carboxylic acids, and 4) ionic organometallic compounds. Currently, we employ two ion chromatography modes for analysis, ion exchange and ion exclusion chromatography. Ion exchange relies on a differential affinity of ionic species for the stationary phase. Primarily, the affinity of analytes to the solid-phase resin of the column (a positively charged quaternary amine) are influenced by the $\mathrm{pH}$ of the eluent. Multiply-charged analytes (phosphate and citrate) elute late, after being fully ionized. Univalent species elute at lower $\mathrm{pH}$. Ion exclusion utilizes a separation dependent on Donnan exclusion and steric effects, as well as partitioning to effect the separation. The solid phase is fully sulfonated, and typically, since the eluting phase is acidic, the stronger acids elute first.

\subsubsection{Sample Analysis}

Liquid chromatography with UV detection was previously used for the analysis of low-molecular weight acids. To quantify organic acids, two procedures were required. For oxalic acid, a Dionex AG4A guard column and Dionex AS4A analytical column were used with $75 \%$ of $1.7 \mathrm{mM} \mathrm{NaHCO}$ and $1.8 \mathrm{mM}$ of $\mathrm{Na}_{2} \mathrm{CO}_{3}$ as the mobile phase. A chromatogram is shown in Figure 3.6. For acetic, formic, and glycolic acids, a Waters ion exclusion column was used with $0.01 \mathrm{~N} \mathrm{H}_{2} \mathrm{SO}_{4}$ as the mobile phase. A chromatogram is shown in Figure 3.7. Figure 3.8 shows an LC chromatogram of a standard mixture of organic acids including citrate, succinic, glycolic, and formic acids with UV detection using anion exclusion chromatography. Figure 3.9 is a chromatogram of a simulated waste sample under the same conditions. Due to the presence of high concentrations of nitrate and nitrite, the quantitation of citrate, succinate, and glycolate was difficult. Dilution of the sample was not a viable option due to the relative insensitivity of detection by UV for organic acids. Alternatively, analysis for combined organic carboxylates in the presence of a tank-simulant matrix is possible using ion chromatography with a gradient elution profile 


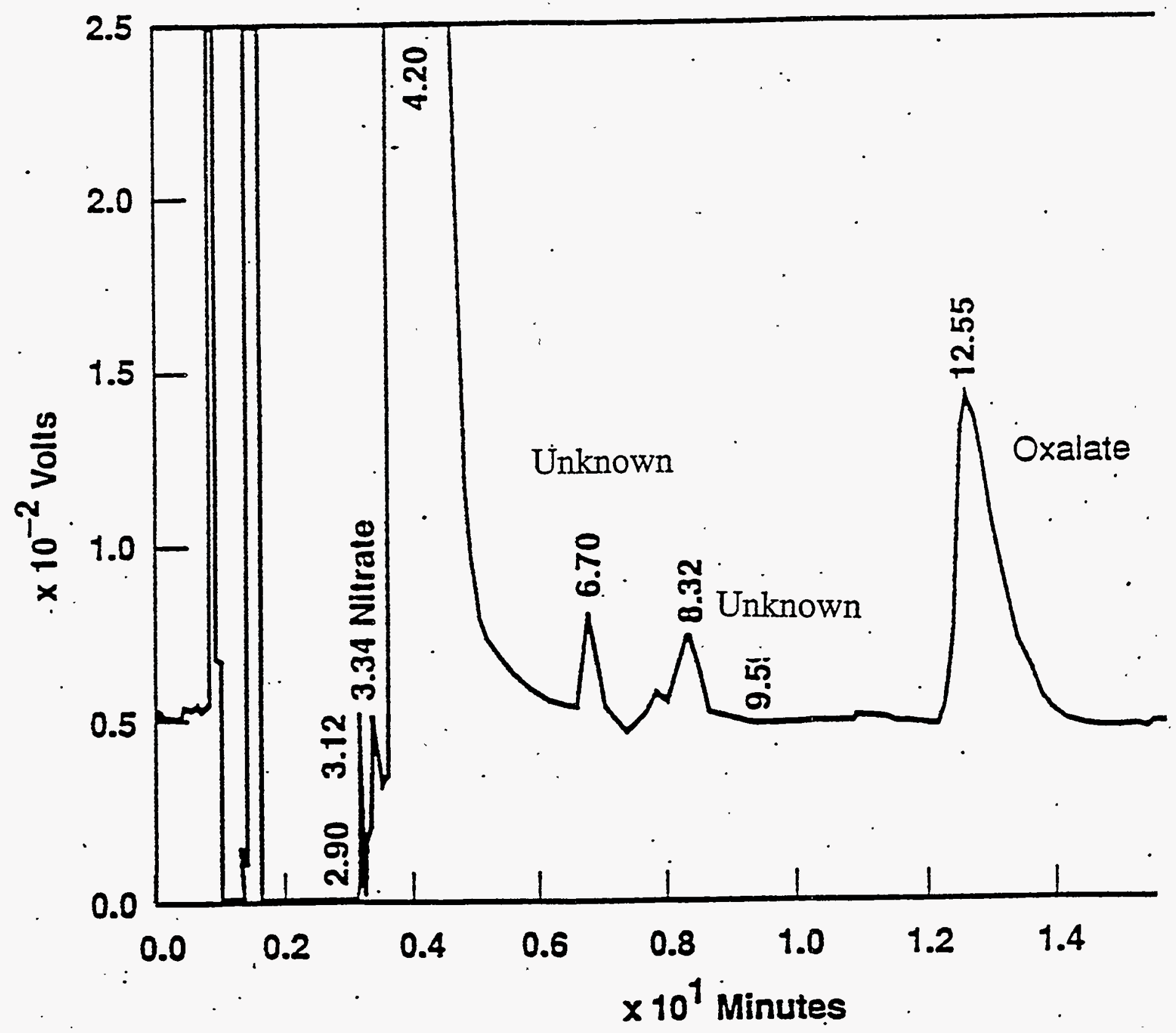

Figure 3.6. LC Chromatogram for Determination of Oxalate 


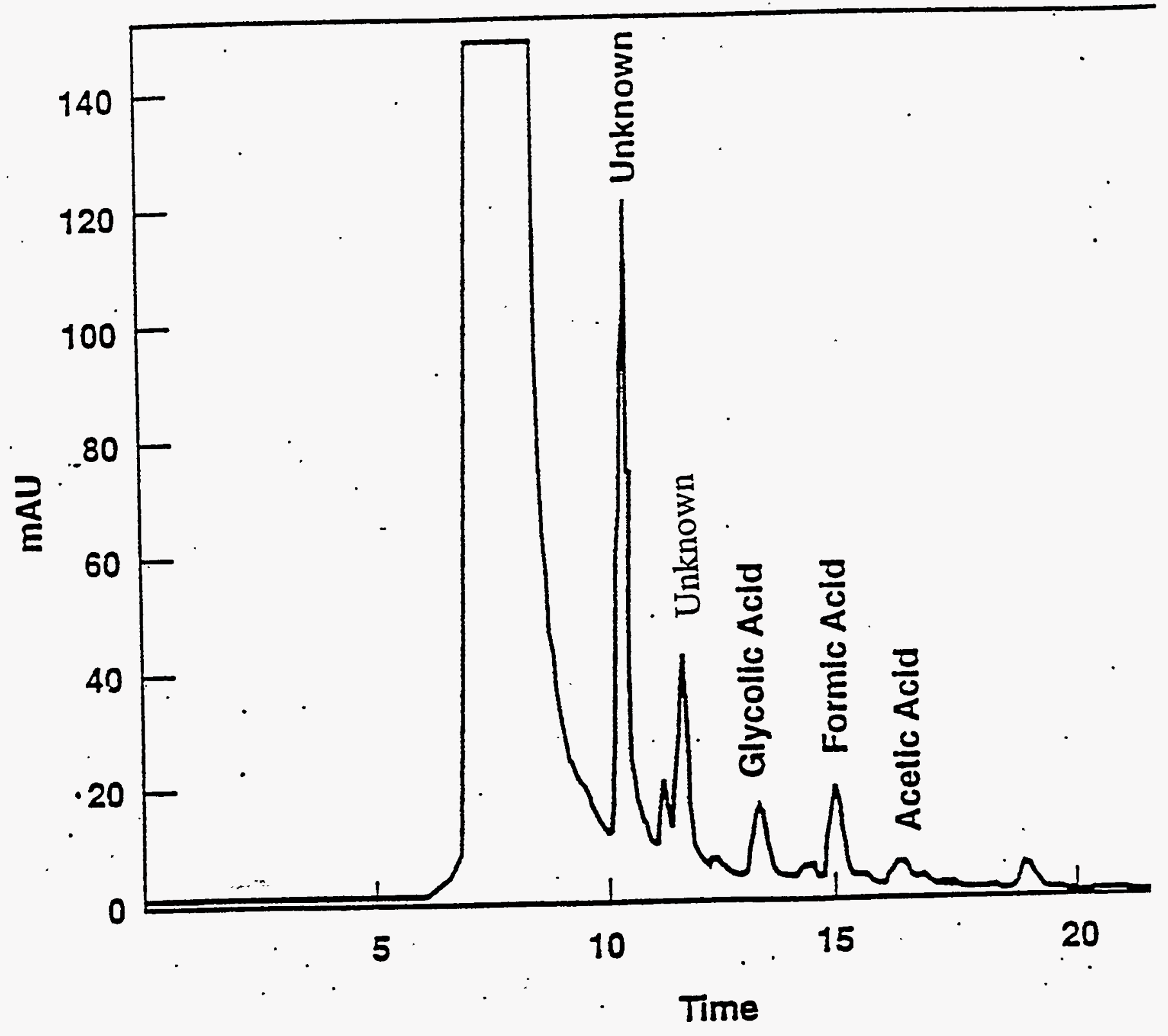

Figure 3.7. LC Chromatogram for Determination of Acetic, Glycolic, and Formic Acids 


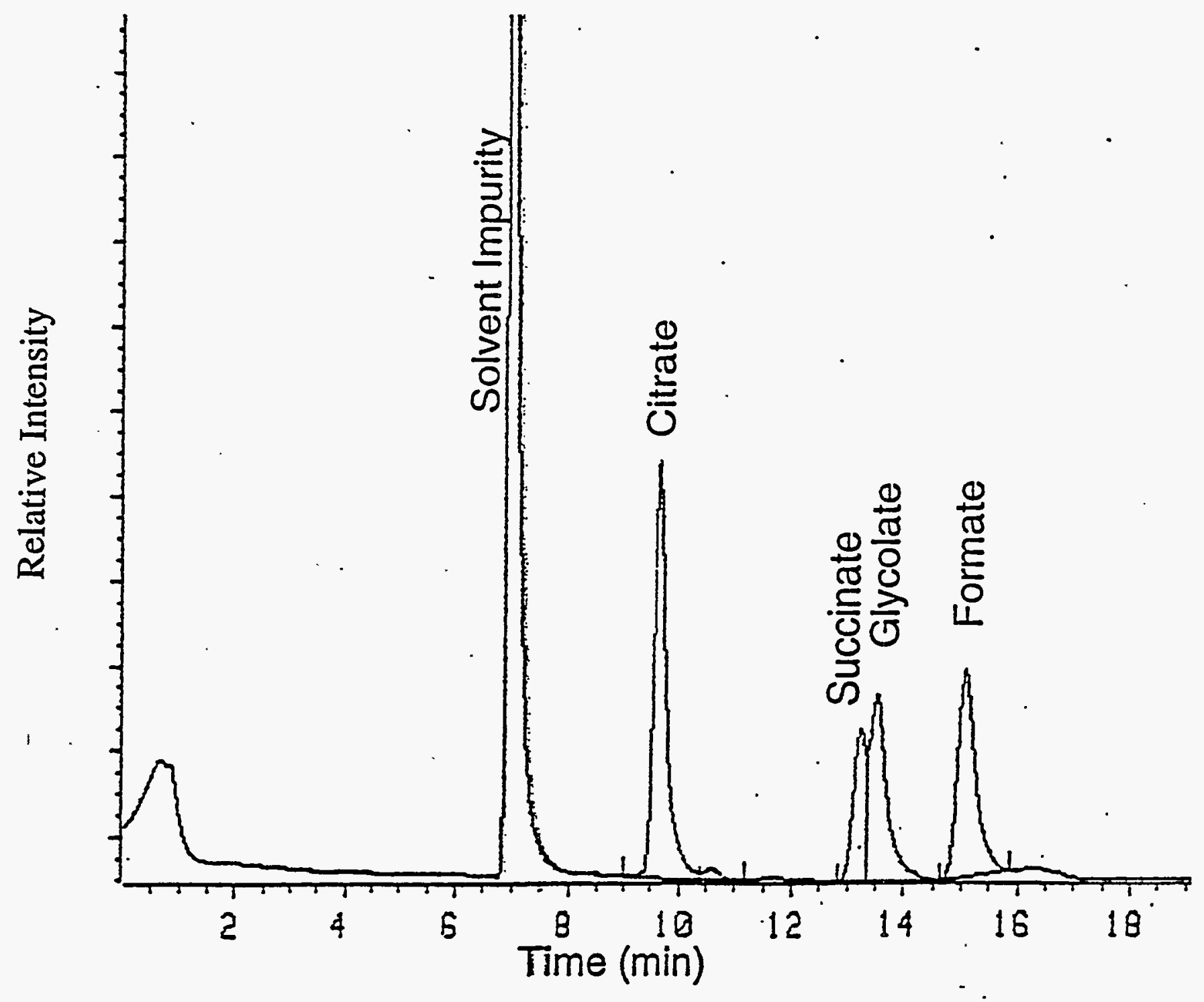

Figure 3.8. LC Chromatogram of Low Molecular Weight Acids Standards (Not in Presence of Simulant) with UV Detection 


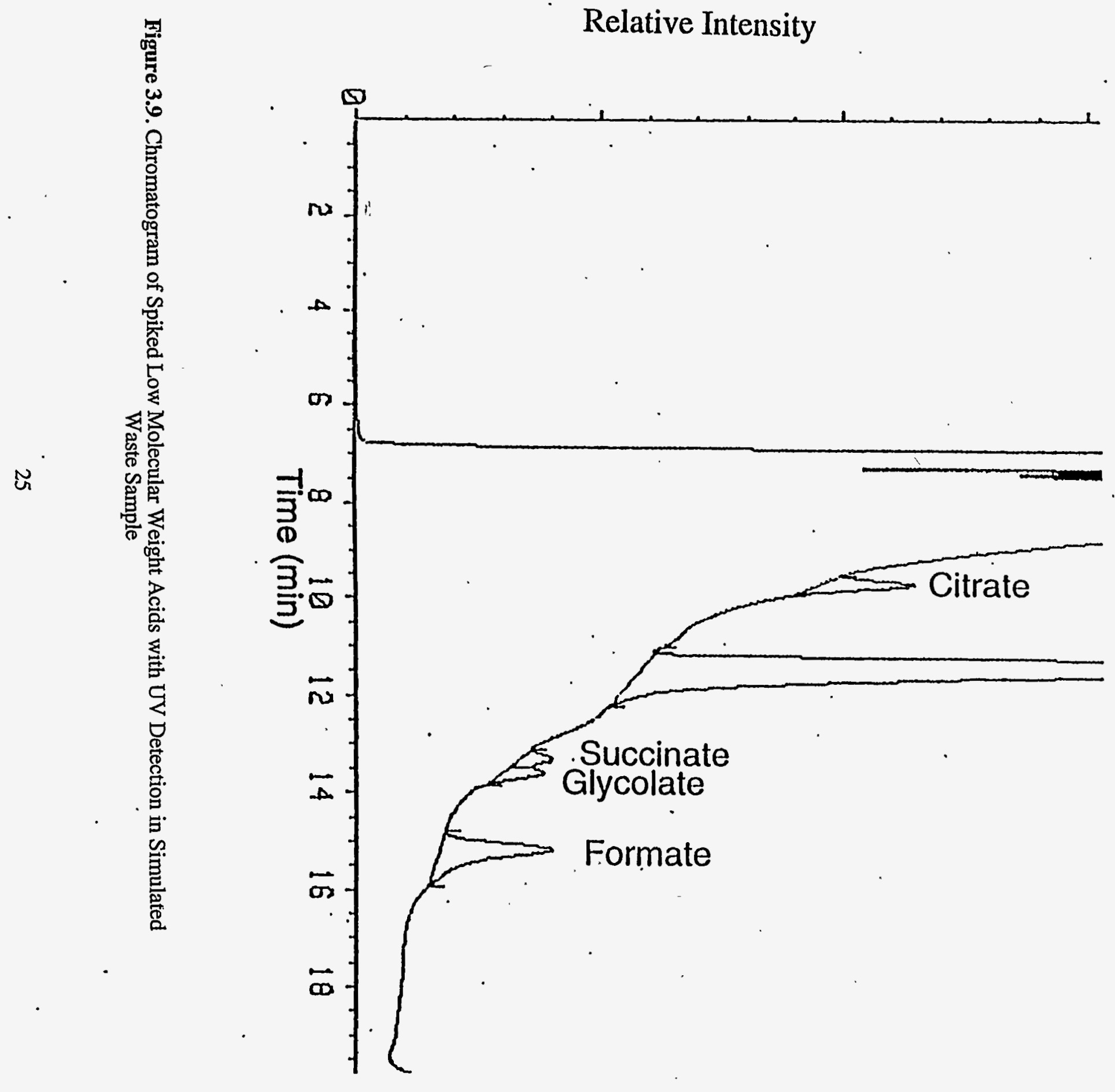


and suppressed conductivity detection. Citrate and succinate analysis using an AS-11 column and separating the acids as carboxylates has been shown to be repeatable and effective in the analysis of several tank-waste simulants. Figure 3.10 is an ion chromatography chromatogram of an organic acids standard with conductivity detection. Figure 3.11 is an ion chromatography chromatogram of a simulated waste sample using conductivity detection. A Dionex AG11 guard column and a Dionex AS-11 analytical column were used with conductivity detection. A step-wise gradient elution program was used with $\mathrm{NaOH}$ as the mobile phase: $0.5 \mathrm{mM} \mathrm{NaOH}$ for $1 \mathrm{~min}, 0.5-5.0 \mathrm{mM} \mathrm{NaOH}$ in $3.5 \mathrm{~min}$, and $5.0-38.25 \mathrm{mM}$ $\mathrm{NaOH}$ in $12 \mathrm{~min}$. Ion chromatography has provided a single, faster, and cheaper method for the analysis of low-molecular-weight acids nearly free of matrix interferences. This method has been successfully applied to simulated wastes and will be used to analyze real wastes.

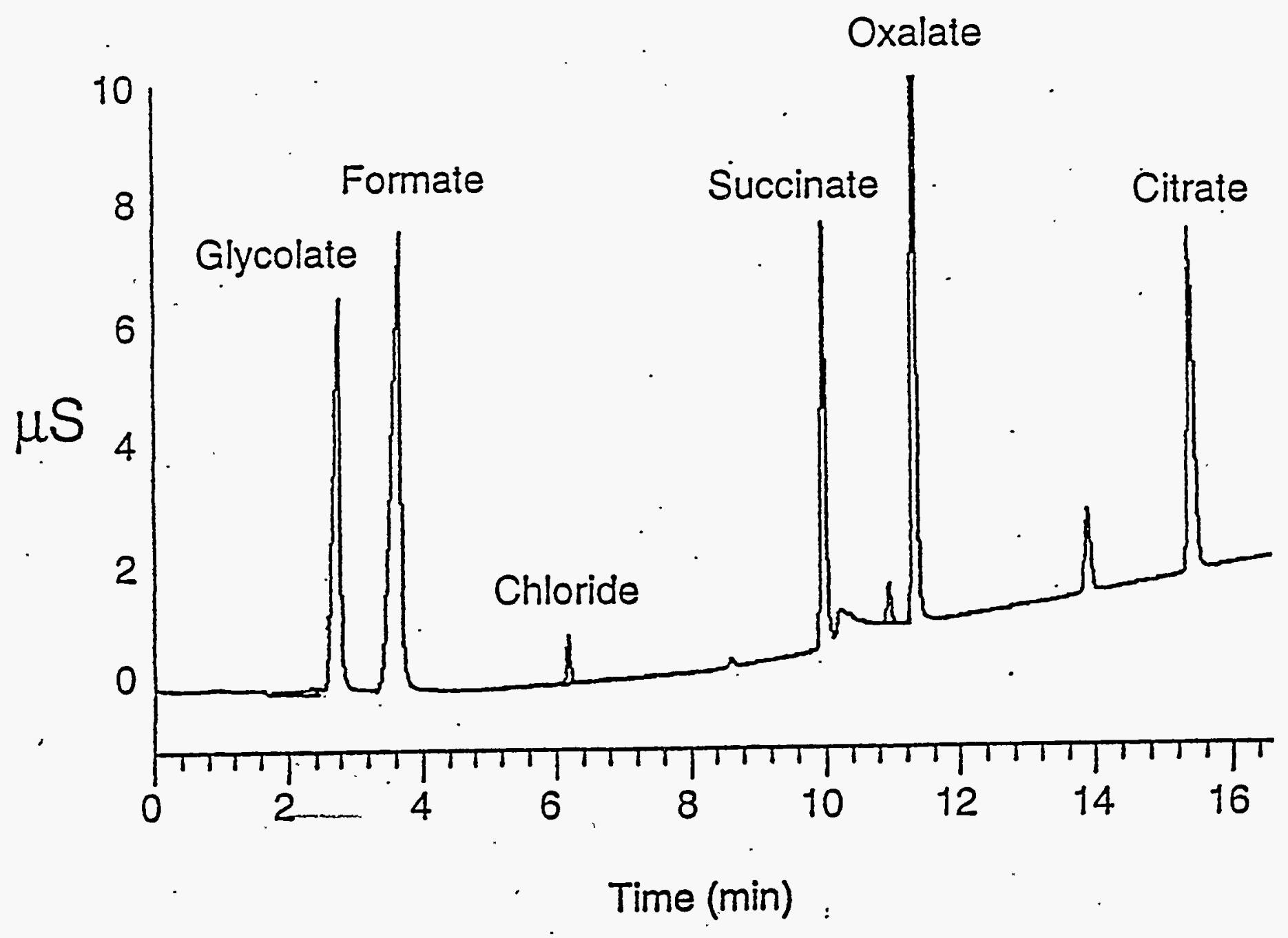

Figure 3.10. Ion Chromatography Chromatogram of an Organic Acids Standard (Not in Presence of Simulated Waste) 


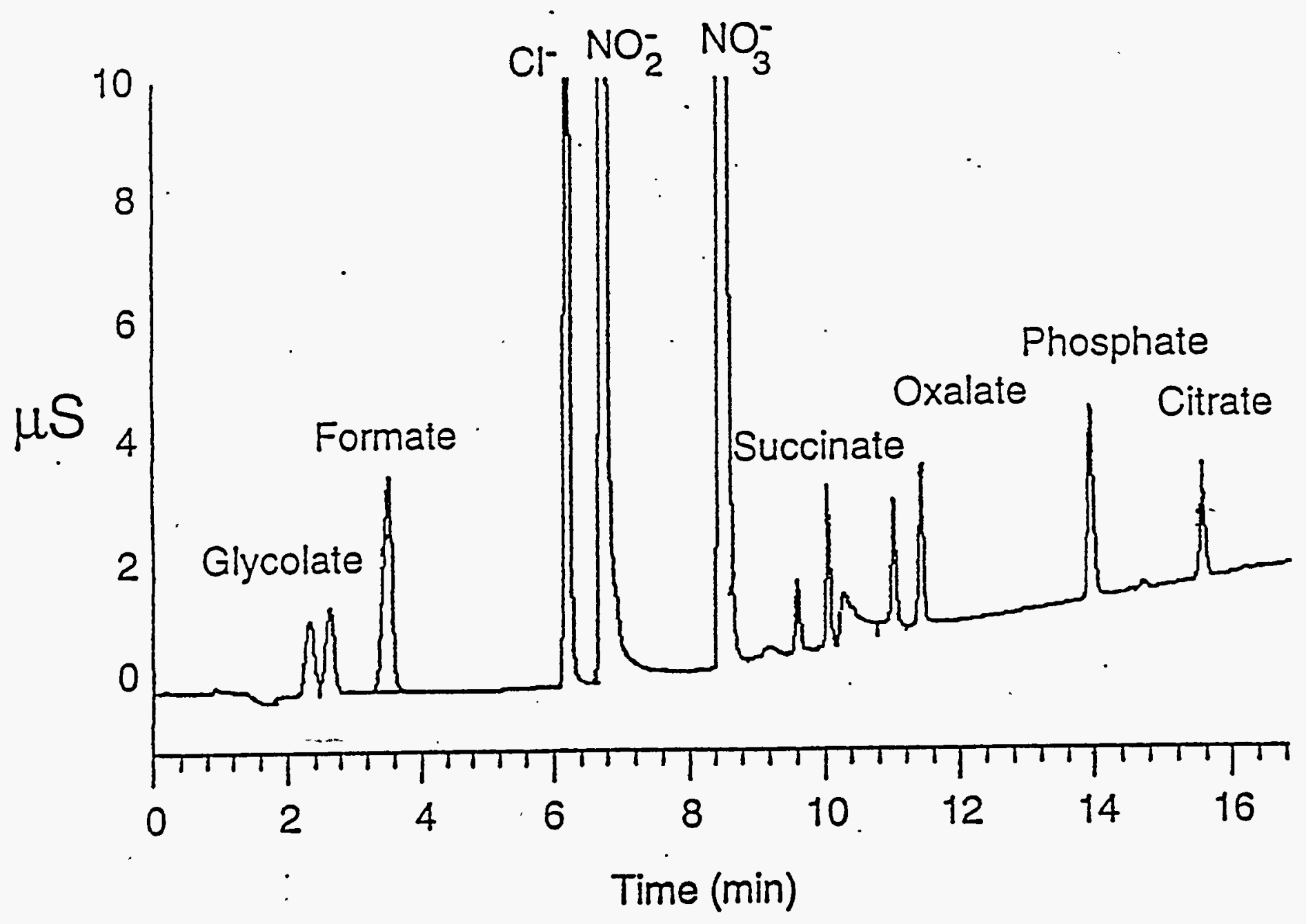

Figure 3.11. Ion Chromatography Chromatogram of a Simulated Waste Using Conductivity Detection 


\subsection{Nitrate/Nitrite Removal}

Two tactics were explored for removing inorganic anions from a simulant matrix. Solid-phase extraction onto a support (ExtreLut@ columns- EM Separations) was examined as a method to trap some of the low-molecular weight acids components from the matrix material as carboxylic acids. This requires that the samples be acidified and introduced through the support media, with the neutral organics remaining on the column. This was felt to be a promising method that would allow the nitrate/nitrite components to be rinsed from the desired components. The unfortunate aspect of such treatment is the necessity of acidifying the sample; this leads to concurrent $\mathrm{NO}_{\mathrm{x}}$ gas generation and probable alteration of certain target organics with active amines (e.g., IDA) to nitroso compounds. Recovery studies were not done.

It was felt that the primary interferent with high performance liquid chromatography (HPLC) analysis for low-molecular weight acids was nitrite. It is well known that sulfamic acid will convert nitrite quantitatively to nitrogen gas, thus relieving the matrix of this material. Again, the problematic aspect of this treatment is the need to acidify the matrix to introduce the sulfamic acid reductant; this leads to concomitant production of nitrous acid and nitroso compounds. The HPLC results obtained on samples given an acidification/sulfamic acid treatment showed marginal improvement for resolution of lowmolecular weight acids from the remaining nitrate. However, at this point we determined that an ion chromatographic separation had distinct advantages over both of these pretreatments.

In consultations with Dan Herting of WHC, who has been working on the clean salt process, . nitrite/nitrate removal was discussed. Briefly, the waste is acidified (converting $\mathrm{NaOH}, \mathrm{Na}_{2} \mathrm{CO}_{3}$, etc. to $\mathrm{NaNO}_{3}$; nitrite disproportionates as well); then the solution is evaporated to crystallize out the $\mathrm{NaNO}_{3}$. The $\mathrm{NaNO}_{3}$ is recrystallized from water until it is virtually free of radionuclides. This method for removal of nitrate and nitrite would not be amenable for incorporation into our sample preparation procedures due to inherent loss of organics.

\subsection{Surfactant Analysis}

Surfactants, as defined here, are long-chain carboxylic acids. As an extension of the derivatization procedure normally used with $\mathrm{BF}_{3} /$ methanol form methyl esters for the analysis of chelators and chelator fragments, long-chain carboxylic acids will also be methylated and can be detected using GC/MS.

Figure $3.12 \mathrm{a}$ is a total ion chromatogram of a concentrated, derivatized nonconvective layer sample from Tank 103-SY. Figure 3.13 indicates the identification of stearic acid in the total ion profile. In addition, Figure 3.14 shows a total ion chromatogram of derivatized eicosanoic acid, C20, and the mass spectrum is shown in Figure 3.15.

For other surfactants with different functional groups, e.g., sulphonates, ion spray MS may be employed for detection and identification (Popenoe et al. 1994). 


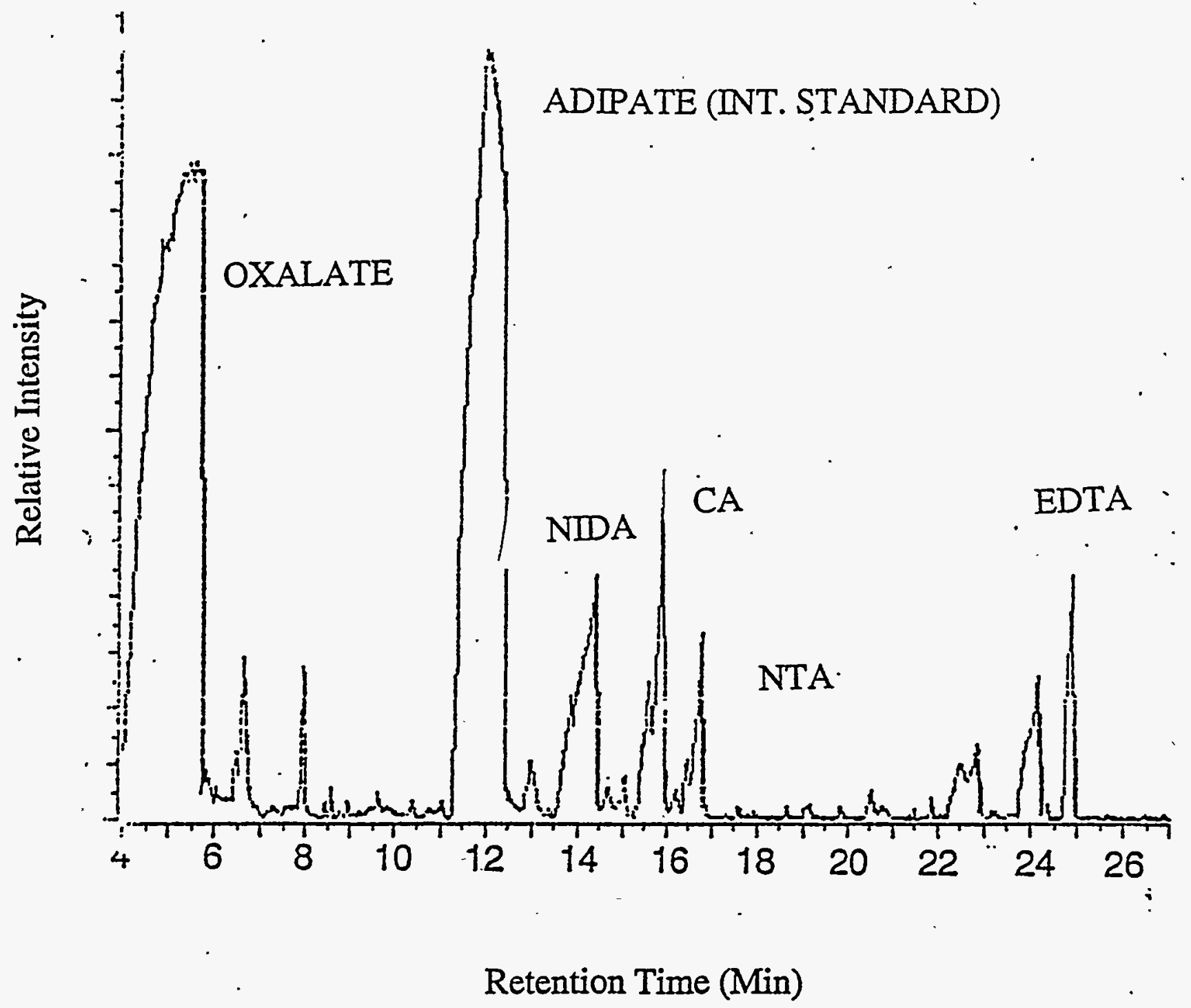

Figure 3.12. Total Ion Chromatogram (GC/MS) of a Concentrated, Derivatized Nonconvective Layer Sample from Tank 103-SY 


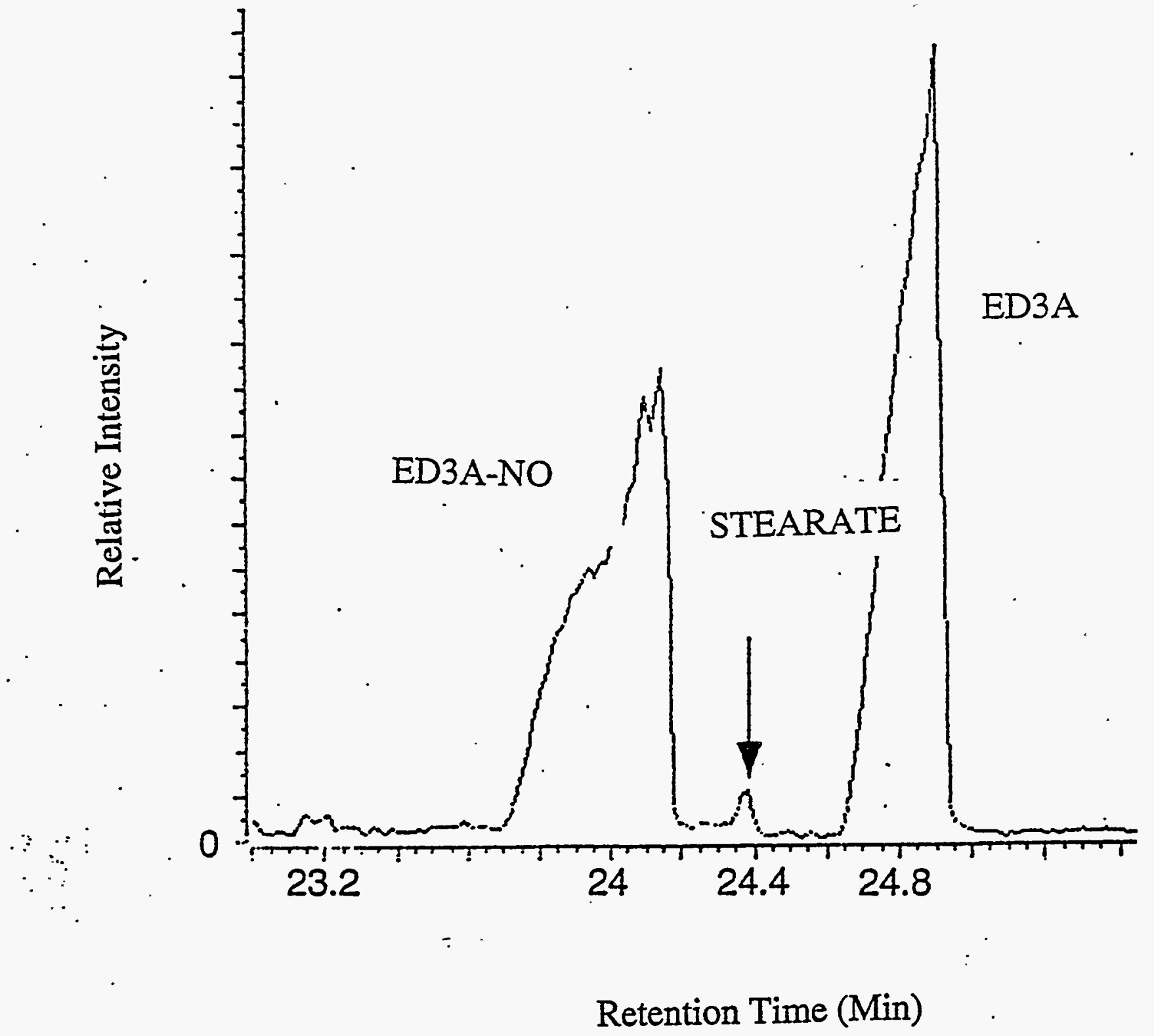

Figure 3.13. Identification of Stearic Acid (C18) in the Total Ion Chromatogram (GC/MS) 


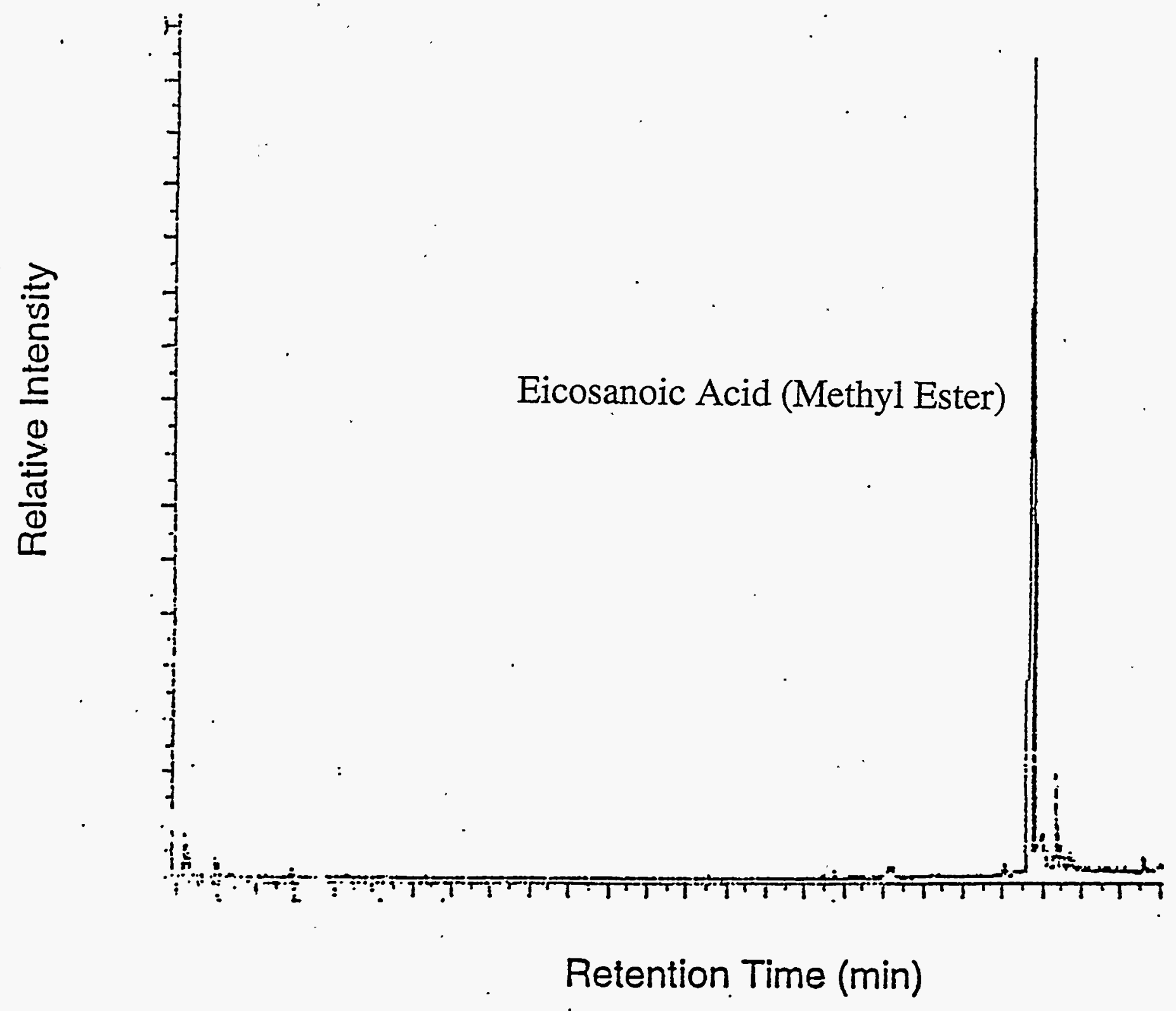

Figure 3.14. Total Ion Chromatogram (GC/MS) of Derivatized Eicosanoic Acid (C20) 


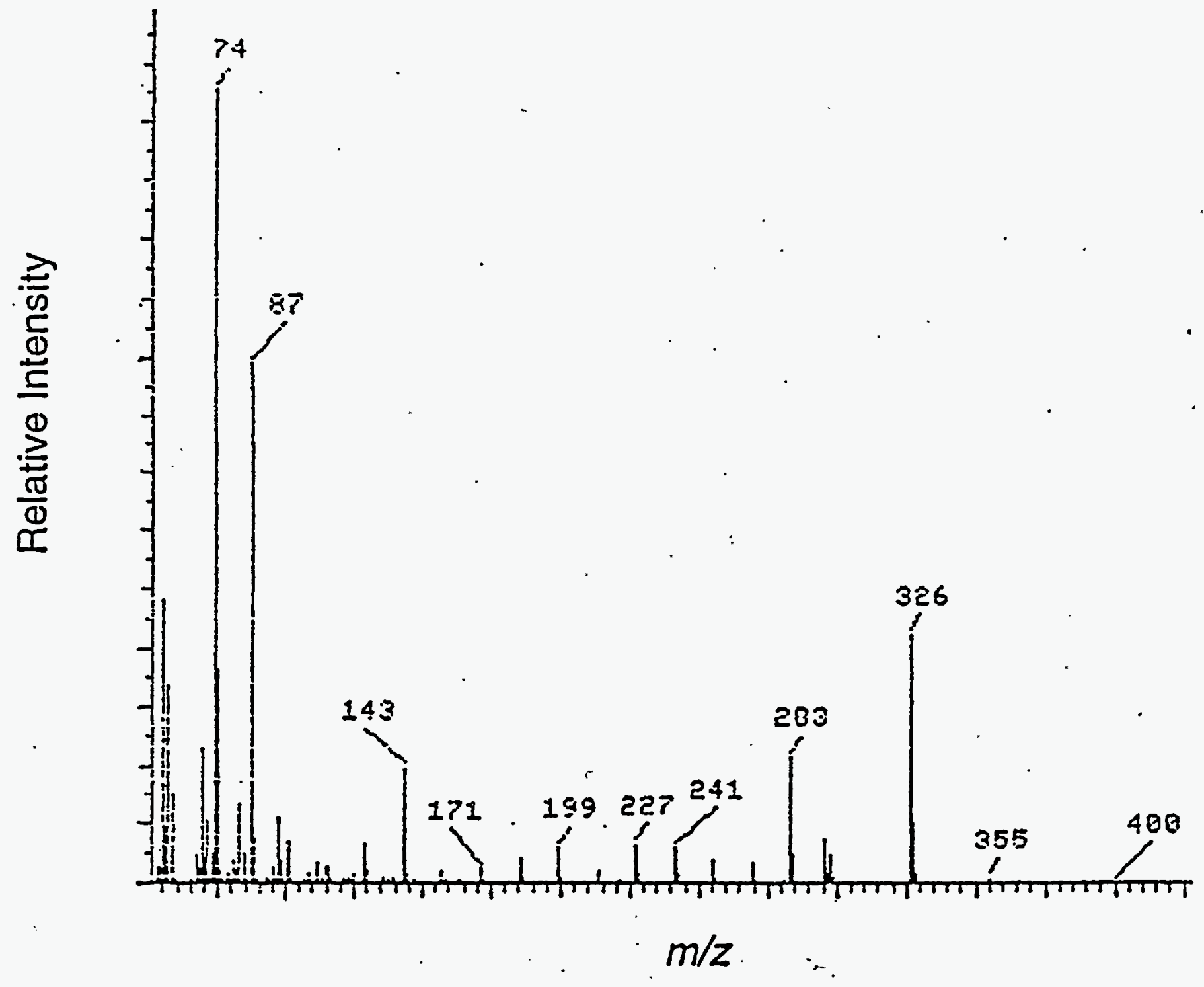

Figure 3.15. Mass Spectrum of Eicosanoic Acid (C20) 


\subsection{Determination of NPH}

Initial efforts focused on the analysis of water-soluble organics. To improve the accountability of TOC, analysis techniques for water-insoluble organics was pursued. The procedure for extracting waterinsoluble organic carbon was conducted in the hot cell. The sludge-like waste sample, at $\mathrm{pH} \approx 13$, was extracted with three equal volumes of chloroform, concentrated, and analyzed using GC/MS. The results from samples of Tank 101-SY are shown in Table 2.8; NPH, $\mathrm{C}_{12}-\mathrm{C}_{15}$, is the primary constituent of the water-insoluble carbon. The concentration of NPH is highest in sample R4258; there is a strong correlation of NPH concentration with depth of the core sample, suggesting a density segregation of NPH. Table S.1 shows the TOC accounted for by chelators, chelator fragments, NPH, and low-molecularweight carboxylic acids in samples from Tank 101-SY. Figure 3.16 is a total ion chromatogram of the chloroform extract of the base-neutral fraction of a Tank 101-SY sample. The peaks indicated are NPH $\left(\mathrm{C}_{12}\right.$ through $\left.\mathrm{C}_{15}\right)$. Because $73-93 \%$ of the TOC can be accounted for in samples from SY-101, very little, if any, water-soluble or water-insoluble carbon remains unidentified. Figure 3.17 is a total ion chromatogram of the chloroform extract of the base-neutral fraction of a Tank 103-SY sample. Total ion chromatogram is a GC/MS term.

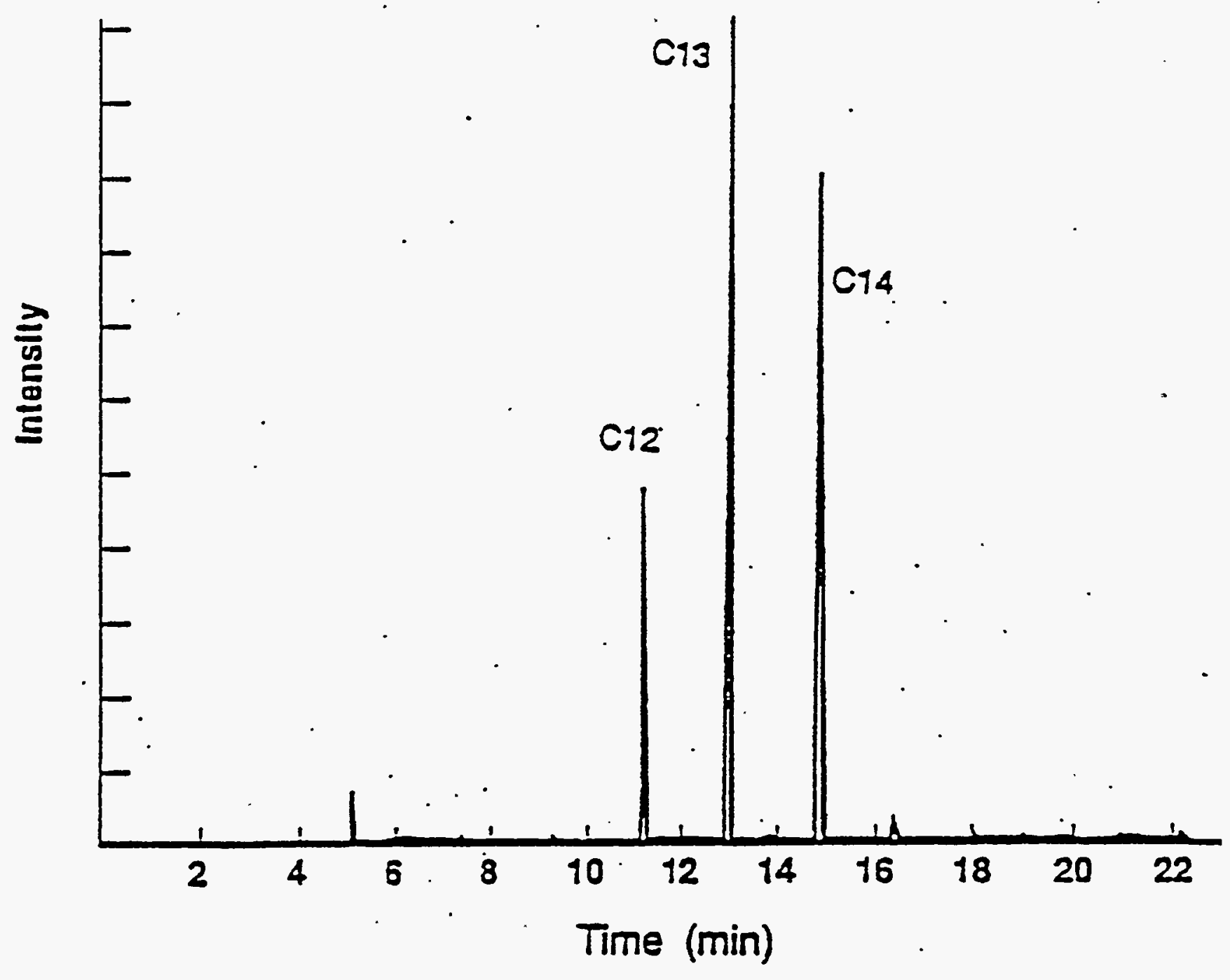

Figure 3.16. Total Ion Chromatogram of the Chloroform Extract of Sample from Tank 101-SY 


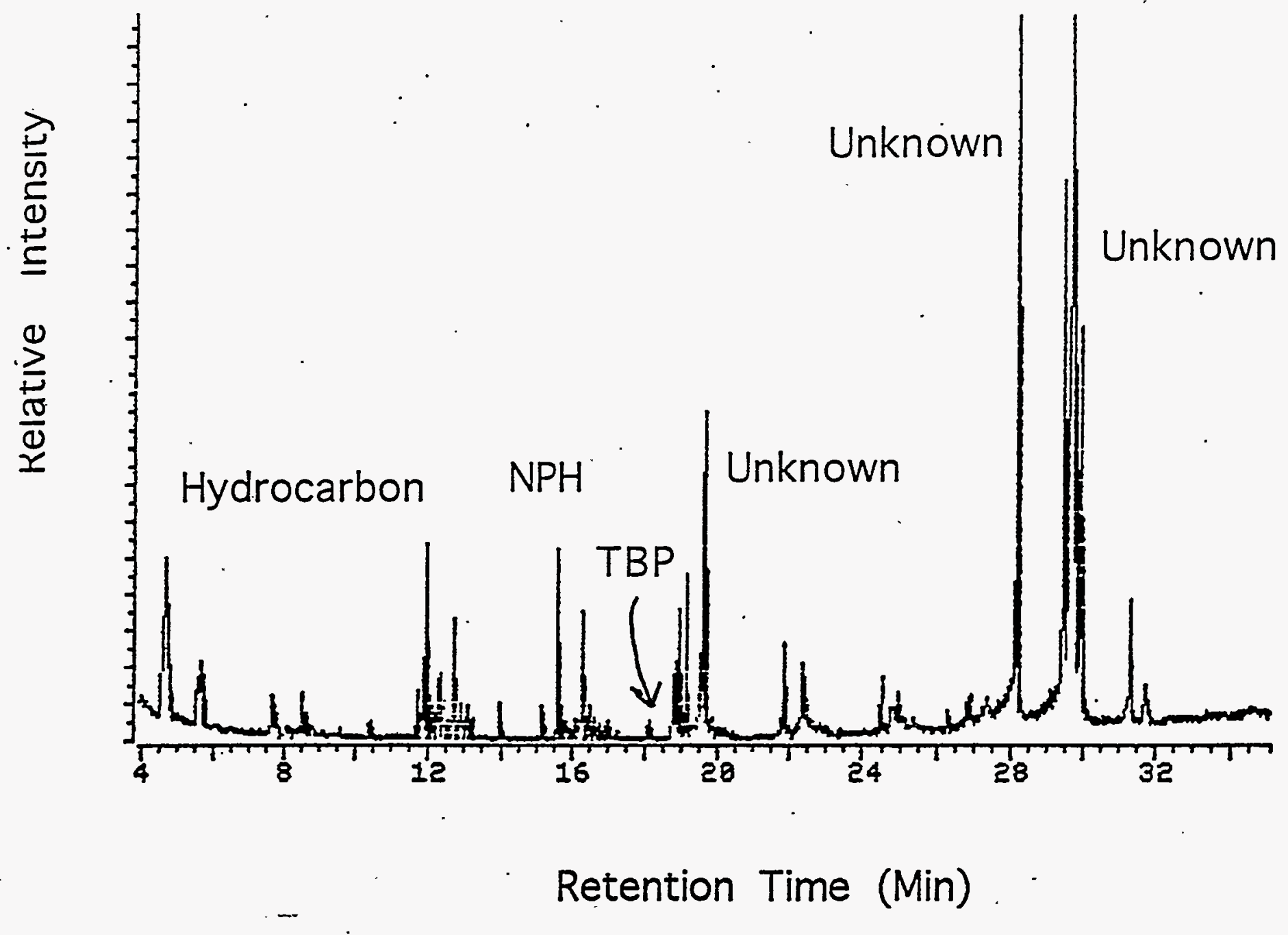

Figure 3.17. Total Ion Chromatogram of Chloroform Extract of Sample from Tank 103-SY 


\subsection{Chemical Support for Simulated Waste Studies}

Results from the analysis of samples 17H8-1A, 17H8-2A, 17H8-1B, and 17H82-B from Sam Bryan have been obtained using HPLC. These samples represent a simulant matrix that has been exposed to combinations of gamma radiation and heating to determine the effects of these treatments on the included organic constituents. Results reported to Sam Bryan indicate reduction of HEDTA and EDTA concentrations following gamma exposure. Bryan et al. have provided additional discussions of results in monthly progress reports for the Flammable Gas Safety Program. Efforts to determine potential degradation products are continuing; in particular, possible routes to determine IDA, one of the logical degradation products, are being explored.

\subsubsection{Reproducibility}

Simulant mixtures were analyzed for chelators and low-molecular weight acids (samples from Sam Bryan) to determine repeatability. The analysis for EDTA and HEDTA of samples designated 17H81A (no gamma exposure), 17H8-2A (gamma exposure), 17H8-1B (no gamma exposure), and 17H8-2B (gamma exposure after heating) was repeated. The analysis was done with duplicate injections of duplicate samples. When combining this with the previously reported results, these samples have been run in triplicate. The percent standard deviations ranged from $2 \%$ in the non-irradiated samples to $20 \%$ in the irradiated samples. The larger value for the irradiated sample reflects the presence of degradation peaks around the base of the target analyte peak. The percent standard deviations in the control sample (17H51) were $4 \%$ for HEDTA and $5 \%$ for EDTA (by area).

Reproducibility in the HPLC analysis of low-molecular weight acids was determined with duplicate weighings with duplicate injections. The analysis, despite additional dilution, again experienced excessive tailing that swamped the target analyte peaks. A method for the analysis of citric acid has been developed using ion chromatography and suppressed conductivity detection. This was necessary because of the interference by high concentrations of nitrite and nitrate in low-molecular weight acids analysis using LC with UV detection. The great advantage in using ion chromatography-conductivity lies in the extremely low detection limits available for the organic acids (sub-part-per-million levels are easily achievable in the sample dilutions), and the ability to completely resolve the interfering $\mathrm{NO}_{2}{ }^{-}$and $\mathrm{NO}_{3}{ }^{-}$ matrix from the targeted carboxylate analytes.

\subsubsection{Ion Chromatography}

The separation mechanism that appears most useful for citric acid and other low-molecular weight acids is an IonPac AS-11 anion exchange column and guard column (Dionex). An isocratic elution using $15 \mathrm{mM} \mathrm{NaOH}$ effectively separates nitrate, nitrite, and phosphate from citrate. In isocratic elution, the mobile phase composition remains constant. Both of the tri-basic species (phosphate and citrate) are baseline separated from 10 - to 50 -fold concentration excesses of nitrate and nitrite. With ion chromatography, the stability of the conductivity baseline and detection limit are both enhanced by using trap columns (to remove traces of unwanted ions from the eluent) and by anion suppression (to remove the carrier eluent hydroxide by neutralization) before detection. These conditions allow a large and sensitive dynamic range for detecting citric acid, which was shown to be linear from a 0.5 -ppm to 50 -ppm solution concentration as injected into the instrument.

Ion chromatographic separation using the AS-11 column follows an elution pattern governed primarily by charge. Monobasic ions such as formate are weakly held; tribasic ions such as citrate are more strongly held by the column. Data exist that indicate a full separation of all anions, including inorganic and organic species, is possible by ramping the eluent $\mathrm{NaOH}$ concentration. For our applications, we have determined the eluent concentration that most effectively elutes nitrite and nitrate; the organic anions formate and acetate elute well before the nitrate/nitrite region, and oxalate, succinate, and citrate elute well after this region. The benefit of true ion chromatographic separation in this case comes from the sensitivity of the analytes to elution strength; that is, small eluent concentration changes can have a marked effect on the affinity of the analyte for the column packing. This should allow the facile creation of a gradient eluent ramp that can separate large concentrations of the offending inorganic ions from any of the targeted organic carboxylates of interest. It is important to note that this work does not represent a large departure from our initial efforts for carboxylate anion analysis. However, to realize 
the full benefit of ion chromatography, it is necessary to use a system capable of supporting conductivity detection. This means that the use of standard LC equipment will not suffice and that all internal parts of the pumps, lines, and fittings should be of polyetheretherketone to limit the amount of stray conducting ions in solution.

Sample containing HEDTA were exposed to gamma radiation for differen $t$ periods of time. Specifically, samples with the prefixes $17 \mathrm{H} 14$ and $17 \mathrm{H} 23$ were analyzed for HEDTA. These samples were assayed by ion-pair chromatography. The samples were run using duplicate injections of duplicate weightings, and the results exhibited a definite correlation between the gamma exposure the samples received and HEDTA content. Additionally, all three non-irradiated samples had the same distribution of HEDTA between the supernatant and solid sample, demonstrating a reproducible result of HEDTA distribution between the two phases. Figure 3.18 is an ion chromatography chromatogram of the inorganic simulant spiked with HEDTA, and Figure 3.19 shows an ion chromatography chromatogram of the degradation products of HEDTA in the solids. Figure 3.20 shows an ion chromatograph chromatogram of the degradation products of HEDTA in the supernate. All of the figures were obtained using gradient elution. 


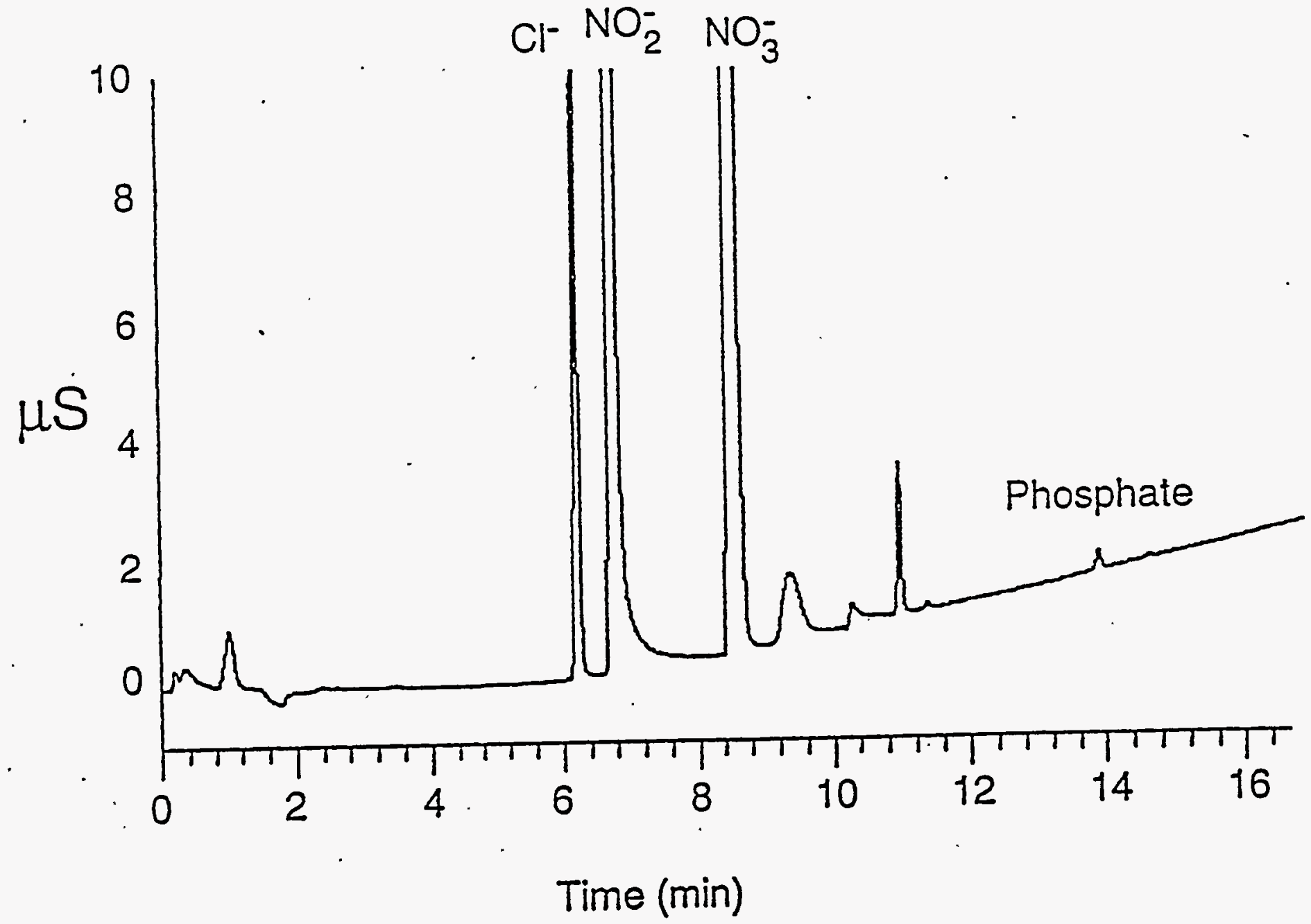

Figure 3.18. Ion Chromatography of Inorganic Simulant Spiked with HEDTA 


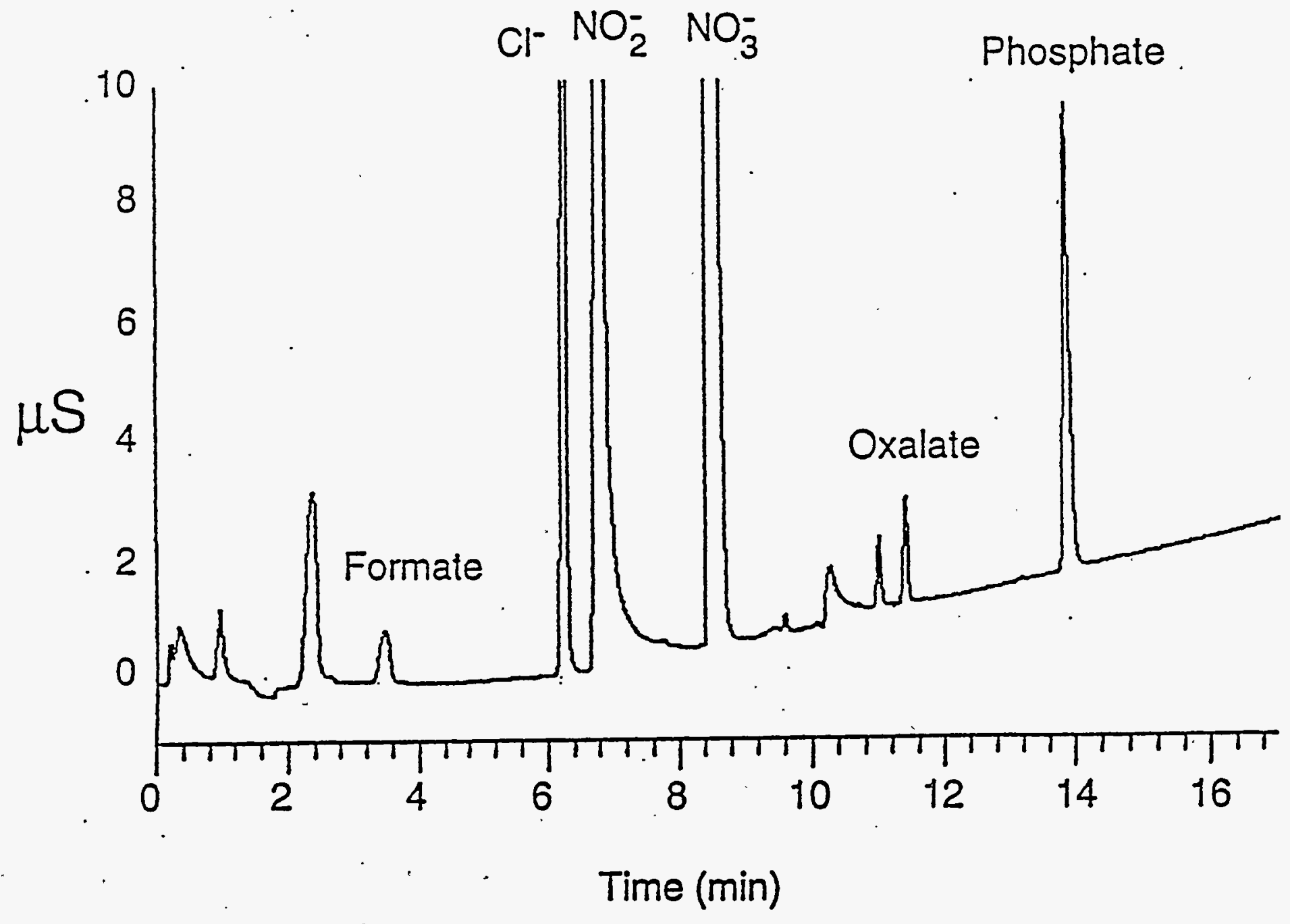

Figure 3.19. Ion Chromatography Chromatogram of Degradation Products of HEDTA in the Solids 


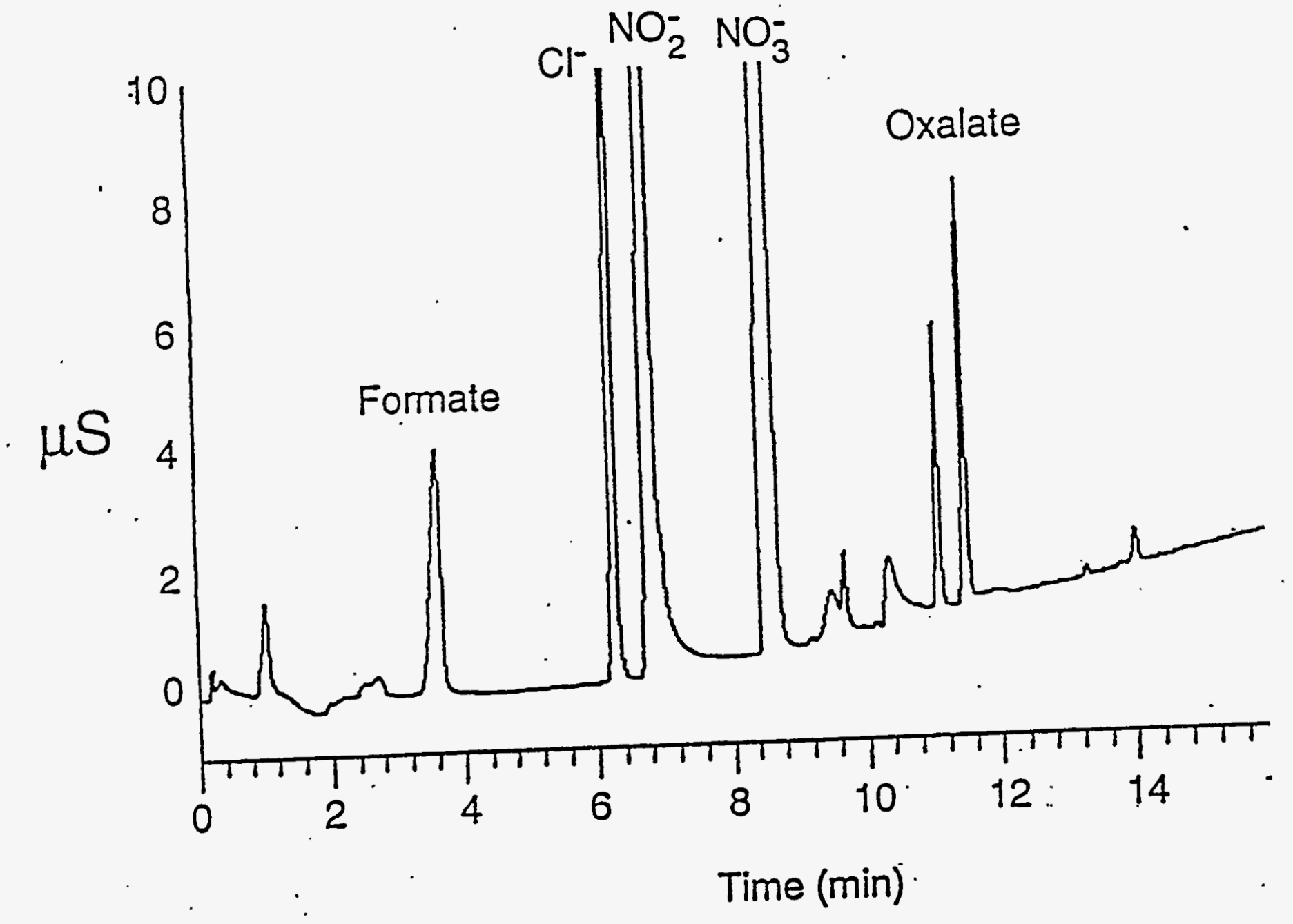

Figure 3.20. Ion Chromatography Chromatogram of Degradation Products of HEDTA in the Supernate 



\subsection{Future Work}

The objective of the Actual Waste Organic Analysis Task is to apply organic analytical methods to flammable gas tank-waste samples to identify and/or quantify the amount of specific organic species. As analytical problems arise (different waste types, interferences, etc.) methods will be modified to produce needed results. Analytical capabilities produced by this task will be used to support other PNL flammable gas tasks such as Gas Generation Studies and Gas Bubble Retention Studies as required and funded by those tasks.

Organic constituents and quantities play a key role in gas composition and generation. Sufficient understanding of organics in tanks other than SY-101 and SY-103 is needed to adequately address the flammable-gas safety issues. The Flammable Gas Program needs to understand the role organics play in how gas is generated, what types of gases are generated, and the quantities of potential or actual flammable gases. Organics provide the source material for some of the flammable gases. The technical challenge has been to adequately analyze samples given changing needs driven by technical questions raised in other parts of the program. While generic organic analytical capabilities may exist elsewhere, this task provides the unique PNL equipment, talent, and experience satisfying the Safety Issue needs as described above. 



\subsection{References}

Baldwin,D. L., R. W. Stromatt, and W. I. Winters. 1994. "Comparative Study of Total Organic Carbon (TOC) Methods for High-Level Mixed Waste", PNL-SA-2374, Richland, Washington.

Barney,G .S. 1994. The Solubilities of Significant Organic Compounds in HLW Tank Supernate Solutions. WHC-SA-24565-FP, Westinghouse Hanford Company, Richland, Washington.

Campbell, J. A., S. A. Clauss, K. E. Grant, F. V. Hoopes, B. D. Lerner, R. B. Lucke, G. M. Mong, J. K. Rau, and R. T. Steele. 1994a Flammable Gas Safety Program. Analytical Methods Development: FY 1993 Progress Report. PNL-9062, Richland, Washington.

Campbell, J. A., S. A. Clauss, K. E. Grant, F. V. Hoopes, B. D. Lerner, R. B. Lucke, G. M. Mong, J. K. Rau, R.T. Steele, and K.L. Wahl. 1994b. Flammable Gas Safety Program. Analytical Methods Development: FY 1994 Progress Report. PNL-10127, Richland, Washington.

Grant,K. E., R. B. Lucke, S. A. Clauss, G. M. Mong, B. D. Lerner, and J. A. Campbell. 1995a. Qualitative Determination of Low-Molecular Weight Acids in Mixed Hazardous Wastes Using Thermospray Liquid Chromatography/Mass Spectrometry, PNL-SA-26295, Submitted to Anal. Chem., Pacific Northwest Laboratory, Richland, Washington.

Grant, K. E., G. M. Mong, R. B. Lucke, and J. A. Campbell. 1995b. Quantitative Determination of Chelators and Their Degradation Products in Mixed Hazardous Wastes Using Derivatization Gas Chromatography/Mass Spectrometry, PNL-SA-26134, Pacific Northwest Laboratory, Richland, Washington.

Lokken, R. O., R. D. Sheele, D. M. Strachan, and A. P. Toste. 1986. Complex Concentrate Pretreatment: FY 1986 Progress Report, PNL-7687, Pacific Northwest Laboratory, Richland, Washington.

Popenoe, D.D., S.J. Morris, III, P.S. Horn, and K.T. Norwood. 1994. Determination of Alkyl Sulfates and Alkyl Ethoxysulfates in Wastewater Treatment Plant Influents and Effluents and in River Water Using Liquid Chromatography/Ion Spray Mass Spectrometry. Anal. Chem., 66, 1620-1629.

Rice, A.D. 1995. 216-Day Final Report for Tank 241-SY-103, Push Mode-Core 62. WHC-SD-WMDP-074, Rev.0, Westinghouse Hanford Company, Richland, Washington.

Small, H., T. S. Stevens, and W. C. Bauman. 1975. Novel Ion Exchange Chromatographic Method Using Conductimetric Detection, Anal. Chem., 47, 1801-1809.

Vànyólos A. 1955. Rev. Chim. (Bucharest), 6, 378-9. 

Appendix A

Experimental Procedures 



\section{Appendix A}

\subsection{Experimental Procedures}

\subsection{Derivatization Gas Chromatography/Mass Spectrometry-Determination of Chelators and Chelator Fragments}

\subsubsection{Waste Sample Extraction/Derivatization}

The waste sample represented a composite of several segments of actual waste obtained by core drilling the waste in Tank 241-SY-101. This material was highly radioactive and contained a high concentration of nitrate and nitrite, and the $\mathrm{OH}^{-}$concentration was $2 \mathrm{M}$. The total organic carbon (TOC) was 1.5 to $2.1 \%$. Convective and Nonconvective-Layer Samples from Tank 103-SY were also analyzed.

\section{Hot-Cell Derivatization Procedure}

Approximately $2 \mathrm{~g}$ of the solids from the composite sample were stirred overnight with $20 \mathrm{~mL}$ of doubly-distilled water. The solution was filtered, and the aqueous solution was evaporated down to dryness in reactivials (VWR Scientific) using nitrogen blowdown techniques. This involves heating the sample while blowing a steady stream of nitrogen over the sample. Approximately $2 \mathrm{~mL}$ of $14 \%$ $\mathrm{BF}_{3} /$ methanol (Aldrich) was added, and the sample was then heated to $100^{\circ} \mathrm{C}$ for $1 \mathrm{~h}$. The solution was cooled, and $1 \mathrm{~mL}$ of chloroform was added. The entire solution was then poured into a test tube containing $2 \mathrm{~mL}$ of $0.1 \mathrm{M} \mathrm{KH}_{2} \mathrm{PO}_{4}$ adjusted to $\mathrm{pH} 7.0$. The reactivial was rinsed with $1 \mathrm{~mL}$ of chloroform, and this was also added to the test tube. The test tube was vortexed, and the aqueous and chloroform layers were allowed to separate. The chloroform layer, containing the derivatized organics, was retained, and the aqueous layer was discarded. At this point, approximately 90 to $95 \%$ of the radioactivity remains with either the aqueous layer or undissolved solid material. The chloroform solution was monitored for radioactivity and then removed from the hot cell for subsequent gas chromatography(GC)/electron impact mass spectrometry (MS) analysis. The derivatized waste sample was also analyzed using positive ion chemical ionization MS to confirm parent ion assignment.

The above procedure was all done in the hot-cell facilities. The hot-cell facilities are used for the preparation, e.g., sample dissolution, dilution, and solvent extraction, and occasionally, the analysis of nuclear wastes. For highly radioactive wastes, e.g., 3 to $11 \cdot \mathrm{R} / \mathrm{h}$, the hot cell must be used. This room is composed of thick walls $(\approx 1.3 \mathrm{~m}$ ) equipped with a sample entry port, viewing windows (leaded glass and oil-filled), and remote manipulators, which are operated by a highly-trained specialist. When a radioactive sample is processed in the hot cell, the procedure is both time consuming and tricky. These procedures cannot be performed by just anyone, anywhere, in any laboratory, when highly radioactive samples are involved. Special training is required. Sample turnaround is much lower when using the hotcell facilities. Wastes with low-to-moderate specific or total radioactivity, $\leq 1 \mathrm{R} / \mathrm{h}$, may be prepared and analyzed outside the hot cell in a radiation hood or glovebox. The actual cutoff levels that differentiate lab bench work, glovebox work, and hot-cell work is usually based upon local practice or the judgment of the resident health physicist. 
An approximately $5 \mathrm{~g}$ quantity of waste was weighed out and stirred with $10 \mathrm{~mL}$ of doublydistilled water overnight. The aqueous phase was filtered through a $0.45-\mu \mathrm{m}$ filter. The filtrate was then passed through a cation exchange column (10 g, AG50W-X8 resin) and rinsed using an additional $10 \mathrm{~mL}$ of water to quantitatively remove the organic material from the resin. The resulting sample volume was $20 \mathrm{~mL}$. After surveying the samples for radioactivity levels, the aqueous solution containing the organics was removed from the hot-cell facilities.

Aliquots $(2 \mathrm{~mL})$ of the sample were transferred to Teflon $^{\circledR}$-sealed vials, evaporated to dryness using nitrogen blow-down techniques, and derivatized with $2 \mathrm{~mL}$ of $\mathrm{BF}_{3} /$ methanol. The sample was heated to $100^{\circ} \mathrm{C}$ for $1 \mathrm{~h}$. The sample was then hydrolyzed with a $\mathrm{KH}_{2} \mathrm{PO}_{4}$ solution and extracted with chloroform as described previously. The chloroform extract was then analyzed by GC/MS.

In calculating the concentration of organic constituents, mechanical extraction loss experienced from the initial 10-mL extraction was estimated by determining the water present in the original samples, adding the $10 \mathrm{~mL}$ of water used for the extraction, and then subtracting the volume of water recovered to determine the mechanical loss. The-water content of samples was determined by measuring the percent solids. (Appendix D)

Aliquots were also measured for liquid chromatography (LC) analysis. Dilutions of the original solutions were usually necessary due to the concentration levels.

Methylation using the reaction with diazomethane, silylation by bis(trimethylsilyl)trifluoroacetamide (BSTFA), butyl esterification with butanol/ $\mathrm{HCl}$, chloroethyl esterification with chloroethanol/HC1, and methylation with $\mathrm{BF}_{3} /$ methanol were carried out on chelator standards obtained from Aldrich and independent sources. All mass spectral analyses were performed on a Hewlett Packard HP 5988A GC/MS system.

Other experimental conditions are described below.

\subsection{2 $\quad \mathrm{BF}_{3} /$ Methanol Methylation}

Reaction of $\mathrm{BF}_{3} / \mathrm{Methanol}$ with chelator standards

Approximately $1 \mathrm{~mL}$ of a $10 \% \mathrm{w} / \mathrm{v}$ solution of boron trifluoride $\left(\mathrm{BF}_{3}\right) /$ methanol (Aldrich) was added to about $5 \mathrm{mg}$ of the chelator in a reaction vial, and the mixture was vortexed and heated for varying lengths of time $(1$ to $5 \mathrm{~h})$ at $100^{\circ} \mathrm{C}$, depending on the chelator being derivatized. Chloroform ( $1 \mathrm{~mL}$ ) was added to the cooled reaction mixture and vortexed. A buffer solution consisting of $1 \mathrm{M}$ $\mathrm{KH}_{2} \mathrm{PO}_{4}$ was made, and the $\mathrm{pH}$ was adjusted to 6.92 using sodium hydroxide. When this buffer solution was added to the contents of the vial, the solution separated into two layers, and an aliquot was pipetted from the bottom layer, the chloroform layer, for GC/MS analysis. Parent ion assignment was confirmed by using positive-ion chemical-ionization MS.

Instrumentation

\subsubsection{GC/MS Conditions.}

The instrument was equipped with an HP $5980 \mathrm{GC}$ operated in the splitless mode. A fused silica column (DB-5, $30 \mathrm{~m}$ X $0.25 \mathrm{~mm}$ id, $0.25-\mu \mathrm{m}$ film thickness, $\mathrm{J} \& \mathrm{~W}$ Scientific) was used. The oven temperature was typically programmed in the following manner: $50^{\circ} \mathrm{C}$ for $1 \mathrm{~min}, 8^{\circ} \mathrm{C} / \mathrm{min}$ to $300^{\circ} \mathrm{C}$, and hold at $300^{\circ} \mathrm{C}$ for $5 \mathrm{~min}$. The MS was tuned daily with perfluorotributylamine (PFTBA). In these studies, the MS was scanned from 50 to $500 \mathrm{amu}$ and operated in the electron impact mode $(70 \mathrm{eV})$. The source temperature was $200^{\circ} \mathrm{C}$, the injector port temperature was $250^{\circ} \mathrm{C}$, and the interfaces were also at $250^{\circ} \mathrm{C}$. 
Chemical ionization was carried out with both methane and isobutane in both positive ion and negative ion chemical ionization modes. The temperature of the source for positive ion chemical ionization MS was $200^{\circ} \mathrm{C}$ and $120^{\circ} \mathrm{C}$ for negative ion chemical ionization. The MS was scanned from 100 to $600 \mathrm{amu}$ in the negative ion mode and 70 to 500 in the positive ion mode.

\subsubsection{Accurate Mass Measurements}

Accurate mass measurements were performed on a VG 70-EHF double-focusing MS equipped with a VG 11-250 data system. The instrument was tuned to a resolution of 5000 (10\% valley definition). Data were acquired by scanning the magnetic field exponentially down over the mass range of 230 to 90 at a rate of $3 \mathrm{sec}$ per mass decade. Instrument tuning and real-time mass measurements were performed by leaking perfluorokerosene into the electron impact ion source from the septum inlet reservoir. Computer-assisted accurate mass assignments and subsequent elemental compositions were made on data obtained from averaging four consecutive scans over the gas chromatographic (GC) elution profile of the analyte. The instrument was equipped with a Varian Model $3700 \mathrm{GC}$. The GC was fitted with $30 \mathrm{~m} \mathrm{X}$ $0.25 \mathrm{~mm}$ id DB-5 capillary column (J \& W Scientific, Folsom, California). The GC oven temperature was held at $50^{\circ} \mathrm{C}$ for $2 \mathrm{~min}$, then programmed at $5^{\circ} \mathrm{C} / \mathrm{min}$ to $250^{\circ} \mathrm{C}$.

\subsection{Analysis of Acid and Base-Neutral Solvent Extracts}

\subsubsection{Sample Preparation}

A 2-g aliquot of a sample ( $\mathrm{pH} 13$ ) was mixed with $10 \mathrm{~mL}$ of methylene chloride and vortexed for $3 \mathrm{~min}$. The solution was filtered and concentrated to approximately $100 \mu \mathrm{L}$ for GC/MS analysis. The $\mathrm{pH}$ of the original solution was then adjusted to 3 with the addition of $\mathrm{HCl}$. The slurry was then mixed with $10 \mathrm{~mL}$ of methylene chloride and vortexed for $3 \mathrm{~min}$. The solution was then filtered and concentrated to approximately $100 \mu \mathrm{L}$ for analysis using GC/MS.

\subsubsection{Instrumentation}

The extracts were analyzed using a JEOL SX 102/SX 102 double focusing tandem MS in the electron impact mode and equipped with a JEOL UNIX data system. Instrument tuning and real-time mass measurements were performed by leaking perfluorokerosene (PFK) into the electron-impact ion source from the septum inlet reservoir. The instrument was equipped with a Hewlett-Packard $5890 \mathrm{GC}$. The GC was fitted with a $30 \mathrm{~m}$ X $0.25 \mathrm{~mm}$ id DB-5 capillary column (J \& W Scientific, Folsom, California). The GC oven temperature was held at $50^{\circ} \mathrm{C}$ for $1 \mathrm{~min}$, then programmed at $8^{\circ} \mathrm{C} / \mathrm{min}$ to $300^{\circ} \mathrm{C}$.

\subsubsection{Instrument Conditions}

\section{Liquid Chromatography}

A Bio-Rad high performance liquid chromatography (HPLC) organic acids column, Aminex Ion Exclusion, HPX-87H, $300 \times 7.8 \mathrm{~mm}$, with compatible guard column was used. The mobile phase for this part of the work was $0.001 \mathrm{~N} \mathrm{HCI}$ (isocratic). The LC oven temperature was $40^{\circ} \mathrm{C}$, and the flow rate was $0.6 \mathrm{~mL} / \mathrm{min}$. A typical run time was $25 \mathrm{~min}$. Standards of organic acids were analyzed using direct flow injection after introduction onto the analytical column. A mixture of organic acids was also analyzed after separation by the analytical column. 


\section{Mass Spectrometry}

The thermospray analyses were performed using the HP 5988A LC/MS in the isocratic mode. The ion source was $275^{\circ} \mathrm{C}$, and the stem initial temperature was $100^{\circ} \mathrm{C}$. Typical values for the tip and the vapor were $230^{\circ} \mathrm{C}$ and $272^{\circ} \mathrm{C}$, respectively. Filament operation was in both the on-and-off modes. The multiplier voltage was $2692 \mathrm{~V}$, and the scan range was either 79 to 500 or 92 to $300 \mathrm{amu}$, depending on the mixtures being analyzed. The injection volume was either $10 \mu \mathrm{L}$ or $20 \mu \mathrm{L}$, depending on the concentration of the sample.

The instrument was tuned with polyethylene glycol (PEG) tuning solution to give maximum abundance of ions. It should be noted that the thermospray ion source should be cleaned approximately once a week to remove nonvolatile chloride salts resulting from the use of $\mathrm{HCl}$ as the mobile phase. Also, since $\mathrm{HCl}$ possesses corrosive effects on metal surfaces, water was flushed through both the HPLC and thermospray system at the end of the day. As long as these cleaning and flushing procedures were followed, no detrimental effects of the thermospray or chromatographic equipment were observed.

\subsubsection{Actual Waste Sample}

The waste sample represented a composite of several segments of actual waste obtained by core drilling the waste in Tank 101-SY. This material was highly radioactive and contained a high concentration of nitrate and nitrite, and the OH- concentration was $2 \mathrm{M}$. The TOC was 1.5 to $2.1 \%$. For samples from Tank 103-SY, an aliquot of the convective layer and nonconvective layer were analyzed.

The actual waste sample was passed through a Bio-Rad analytical-grade cation exchange column (AG 50W-X8, 50-100 mesh, hydrogen form) in a remote handling hot cell that removed almost all of the radioactivity due to primary fission products in the waste (sometimes down to nearly background levels) before being brought to the instruments for analysis. The hot-cell facilities are used for the preparation, e.g., sample dissolution, dilution, and solvent extraction, and occasionally, the analysis of nuclear wastes. For highly radioactive wastes, e.g., 3 to $11 \mathrm{R} / \mathrm{h}$, the hot cell must be used. This room is composed of thick walls $(\approx 1.3 \mathrm{~m}$ ) equipped with a sample entry port, viewing windows (leaded glass and oil-filled), and remote manipulators, which are operated by a highly-trained specialist. When a radioactive sample is processed in the hot cell, the procedure is both time consuming and difficult. These procedures can not be performed by just anyone, anywhere, in any laboratory, when highly radioactive samples are involved. Special training is required. Sample turnaround is much lower when using the hot-cell facilities. Wastes with low-to-moderate specific. or total radioactivity, $\leq 1 \mathrm{R} / \mathrm{h}$, may be prepared and analyzed outside the hot cell in a radiation hood or glovebox. The actual cutoff levels that differentiate lab bench work, glovebox work, and hot-cell work is usually site specific, based upon local practice or the judgment of the resident health physicist.

A 1-g aliquot of the waste sample was weighed and placed in a $25.0-\mathrm{mL}$ volumetric flask. The sample was then neutralized with $0.001 \mathrm{~N} \mathrm{HCl}$ to the $\mathrm{pH}$ of the mobile phase using an Orion extendedscale $\mathrm{pH}$ meter. The solution was then diluted to volume using Milli-Q water. An aliquot of the solution was filtered into an $\mathrm{LC}$ vial using a Gelman Acrodisc LC13, 0.45- $\mu \mathrm{m}$ syringe-tip filter. Approximately 20 $\mu \mathrm{L}$ was used for HPLC or thermospray LC/MS analysis.

\subsection{Radioactivity Reduction Using Cation Exchange}

Analyses for ${ }^{137} \mathrm{Cs}$ were performed according to PNL-ALO-464. All analyses were performed on empirically calibrated Germanium detectors with identical geometries. All data reduction was performed using Canberra gamma analysis and data-reduction software. The results indicate an approximate factor of 300 reduction of ${ }^{137} \mathrm{Cs}$ in the material from the convective layer released from the hot cell for our benchtop studies with respect to the activity of the neat samples. All ${ }^{90} \mathrm{Sr}$ analyses were performed according to PNL-ALO-476,474, and 464. Appropriate aliquots were taken and spiked with ${ }^{86} \mathrm{Sr}$. The $\mathrm{Sr}{ }^{-}$ was then separated by column chromatography from ${ }^{90} \mathrm{Y}$ and other impurities. The Sr fraction was eluted and counted by gamma energy analysis (GEA) for yield using a prepared comparitor made at the time of spiking. The Sr fraction was then allowed to sit several days to allow the ${ }^{90} \mathrm{Y}$ daughter to ingrow. After ingrowth, the $\mathrm{Y}$ daughter was counted several times on a liquid scintillation counter using cherenkow 
radiation with counter efficiency calculated from standards of known activity. The $Y$ activity was then derived to determine the activity. Gross alpha analyses were performed according to PNL-ALO-460. Appropriate aliquots were dried onto planchets and counted on proportional alpha scintillation detectors. The results of gross alpha analyses of samples before and after cation exchange elution are also shown in

Table 2.7 .

\subsection{Ion Chromatography}

Ion chromatography experimentation was conducted with a Dionex Ion Chromatograph. Citrate and succinate analysis using an AS-11 column and separating the acids as carboxylates has been shown to be repeatable and effective in the analysis of several tank-waste simulants. Figure 3,10 is an ion chromatography chromatogram of an organic acids standard with conductivity detection. Figure 3.11 is an ion chromatography chromatogram of a simulated waste sample using conductivity detection. A Dionex AG11 guard column and Dionex AS-11 analytical column was used with conductivity detection. A stepwise gradient elution program was used with $\mathrm{NaOH}$ as the mobile phase: $0.5 \mathrm{mM} \mathrm{NaOH}$ for $1 \mathrm{~min}, 0.5$ $5.0 \mathrm{mM} \mathrm{NaOH}$ in $3.5 \mathrm{~min}$, and $5.0-38.25 \mathrm{mM} \mathrm{NaOH}$ in $12 \mathrm{~min}$.

\subsection{Gas Chromatography/Flame Ionization Detection}

The GC/flame ionization detection was used for quantification of organic components. The instrument was a HP $5980 \mathrm{GC}$ operated in the splitless mode. A fused silica column (DB-5, $30 \mathrm{~m}$ X 0.25 $\mathrm{mm}$ id, $0.25-\mu \mathrm{m}$ film thickness, J \& W Scientific) was used. The oven temperature was typically programmed in the following manner: $50^{\circ} \mathrm{C}$ for $1 \mathrm{~min}, 8^{\circ} \mathrm{C} / \mathrm{min}$ to $300^{\circ} \mathrm{C}$, and hold at $300^{\circ} \mathrm{C}$ for $5 \mathrm{~min}$. The detector tempeature was $260^{\circ} \mathrm{C}$. 



\section{Distribution}

No. of

\section{Copies}

Offsite

2 DOE/Office of Scientific and Technical Information

Steve F. Agnew

Los Alamos National Laboratory

P. O. Box 1663

Los Alamos, NM 87545

J. Antizzo

U.S. Department of Energy

EM-36/Trevion II

Germantown, MD 20874

Dr. E. C. Ashby

School of Chemistry/Biochemistry

Georgia Institute of Technology

Atlanta, GA 30332-0400

Dr. E. K. Barefield

School of Chemistry/Biochemistry

Georgia Institute of Technology

Atlanta, GA 30332-0400

Ned Bibler

Westinghouse Savannah River

P. O. Box 616

Aiken, SC 29802

2 Jack Edwards

Los Alamos National Laboratory

P. O. Box 1663

Los Alamos, NM 87545

L. Kovach

NUCON

P. O. Box 29151

Columbus, $\mathrm{OH}$ 43229-0151

B. R. Kowalski

Chemistry Department, BG-10

University of Washington

Seattle, WA 98195

C. L. Liotta

School of Chemistry/Biochemistry

Georgia Institute of Technology

Atlanta, GA 30332-0400
No. of

Copies

Dr. D. Meisel

Chemistry Division

Argonne National Laboratory

9700 S. Cass Ave.

Agronne, IL 60439

H. M. Neumann

School of Chemistry/Biochemistry

Georgia Institute of Technology

Atlanta, GA 30332-0400

C. O'Dell

U.S. Department of Energy

EM 36/Trevion III

Germantown, MD 20874

D. Pepson

U.S. Department of Energy

19901 Germantown, MD 20874-1290

Wally Schulz

727 Sweetlead Drive

Wilmington, DE 19808

Dr. L. M. Stock

Chemistry Division

Argonne National Laboratory

9700 South Cass Avenue

Argonne, IL 60439

H. Sutter

SAIC

20300 Century Blvd.

Germantown, MD 20874

Onsite

7 DOE Richland Operations Office

S. O. Branch S7-54

R. F. Christensen S7-54

M. F. Jarvis • S7-54

G. W. Rosenwald $\quad$ S7-54

Public Reading Room

RL Docket File (2)

FAI .

M. G. Plys H4-62

Distr. 1 
No. of

\section{Copies}

$\dot{2}$

MACTEC

M: H. Campbell

S7-73

S. T. Murff

14 Westinghouse Hanford Company
H. Babad
R2-78
G. S. Barney
T5-12
D. B. Bechtold
T6-09
G. T. Dukelow
S7-15
K. A. Gasper
G3-21
D. L Herting
T6-09
.J. D. Hopkins
R2-11
J. R. Jewett
T6-09
G. D. Johnson
S7-15
N. W. Kirch
R2-11
N. G. McDuffie
S7-15
J. C. Person
T6-09
D. A. Reynolds
R2-11
D. A. Tumer
S7-15

49 Pacific Northwest Laboratory G. H. Beeman

J. W. Brothers

S. A. Bryan

K5-22

D. M. Camaioni

P7-25

J. A. Campbell (10)

$\mathrm{K} 2-44$

S. A. Clauss

P. A. Gauglitz

P8-08

P8-08

M. A. Gerber

P7-41

S. C. Goheen

P8-38

R. T. Hallen

L. K. Holton

P8-08

D. W. Koppenaal

P8-38

K9-73

P7-07

B. D. Lerner

P8-08

M. A. Lilga

P8-38

G. M. Mong

P8-08

L. R. Pederson

K2-44

W. D. Samuels

K2-44

R. D. Scheele

P7-25

L. A. Schienbein

K5-20

A. K. Sharma

P8-08

C. W. Stewart

K7-15

M. R. Thompson

$\mathrm{K} 2-50$

J. M. Tingey

P7-25

J. J. Toth

K7-94

K. L. Wahl (10)

P8-08

Organic Tank Project File $\quad$ K9-89

Publishing Coordination

Technical Report Files (5)

Distr. 2 